Review Article

\title{
Androgen Effects on the Adrenergic System of the Vascular, Airway, and Cardiac Myocytes and Their Relevance in Pathological Processes
}

\author{
Abril Carbajal-García, Jorge Reyes-García, and Luis M. Montaño \\ Departamento de Farmacología, Facultad de Medicina, Universidad Nacional Autónoma de México, CDMX, Mexico \\ Correspondence should be addressed to Luis M. Montaño; lmmr@unam.mx
}

Received 12 August 2020; Revised 17 September 2020; Accepted 20 October 2020; Published 12 November 2020

Academic Editor: Paola Llanos

Copyright ( 2020 Abril Carbajal-García et al. This is an open access article distributed under the Creative Commons Attribution License, which permits unrestricted use, distribution, and reproduction in any medium, provided the original work is properly cited.

\begin{abstract}
Introduction. Androgen signaling comprises nongenomic and genomic pathways. Nongenomic actions are not related to the binding of the androgen receptor (AR) and occur rapidly. The genomic effects implicate the binding to a cytosolic AR, leading to protein synthesis. Both events are independent of each other. Genomic effects have been associated with different pathologies such as vascular ischemia, hypertension, asthma, and cardiovascular diseases. Catecholamines play a crucial role in regulating vascular smooth muscle (VSM), airway smooth muscle (ASM), and cardiac muscle (CM) function and tone. Objective. The aim of this review is an updated analysis of the role of androgens in the adrenergic system of vascular, airway, and cardiac myocytes. Body. Testosterone $(\mathrm{T})$ favors vasoconstriction, and its concentration fluctuation during life stages can affect the vascular tone and might contribute to the development of hypertension. In the VSM, T increases $\alpha 1$-adrenergic receptors ( $\alpha_{1}$-ARs) and decreases adenylyl cyclase expression, favoring high blood pressure and hypertension. Androgens have also been associated with asthma. During puberty, girls are more susceptible to present asthma symptoms than boys because of the increment in the plasmatic concentrations of T in young men. In the ASM, $\beta_{2}$-ARs are responsible for the bronchodilator effect, and Taugments the expression of $\beta_{2}$-ARs evoking an increase in the relaxing response to salbutamol. The levels of $\mathrm{T}$ are also associated with an increment in atherosclerosis and cardiovascular risk. In the CM, activation of $\alpha_{1 \mathrm{~A}}$-ARs and $\beta_{2}$-ARs increases the ionotropic activity, leading to the development of contraction, and T upregulates the expression of both receptors and improves the myocardial performance. Conclusions. Androgens play an essential role in the adrenergic system of vascular, airway, and cardiac myocytes, favoring either a state of health or disease. While the use of androgens as a therapeutic tool for treating asthma symptoms or heart disease is proposed, the vascular system is warmly affected.
\end{abstract}

\section{Introduction}

1.1. Metabolic Pathways of Steroids. Testosterone (T), the main testicular hormone, is produced by Leydig cells in high concentrations (95\%). However, smaller amounts of $\mathrm{T}$ are also synthesized by the adrenal cortex [1-4]. The production and secretion of this androgen are regulated through luteinizing hormone (LH) stimulation. Cholesterol is the precursor of $\mathrm{T}$, and the steroidogenesis is carried out through cytochrome P450 enzymes [5]. The conversion of cholesterol to pregnenolone is the first step in producing $\mathrm{T}$ and is accomplished by the P450 side-chain cleavage enzyme
(P450cc/CYP11A1) $[4,5]$. Subsequently, this progestogen is biotransformed either to $17 \alpha$-hydroxypregnenolone or to progesterone via $\mathrm{P} 450 \quad 17 \alpha$-hydroxylase (P450c17/ CYP17A1) and $3 \beta$-hydroxysteroid dehydrogenase type 2 (3 $\beta$-HSD2), respectively. Afterward, 17 $\alpha$-hydroxypregnenolone is converted to dehydroepiandrosterone (DHEA) by cytochrome P450c17/CYP17A1 [5-7]. The conversion of DHEA to androstenedione via $3 \beta$-HSD2 or to androstenediol via $17 \beta$-hydroxysteroid dehydrogenase $(17 \beta$-HSD3) is followed by the biotransformation to T by $17 \beta$-HSD 3 or $3 \beta$-HSD2, respectively [5]. Furthermore, $T$ is either reduced to $5 \alpha$-dihydrotestosterone ( $5 \alpha$-DHT) by $5 \alpha$-reductase or to 
$5 \beta$-dihydrotestosterone ( $5 \beta$-DHT) by $5 \beta$-reductase [8-10]. Additionally, T can be converted to $17 \beta$-estradiol (E2) via the aromatase (P450aro/CYP19A1) action, and 17 $\beta$-HSD3 catalyzes the formation of E2 from estrone (Figure 1) [5].

In women, $\mathrm{T}$ is produced and secreted by the ovarian stroma, particularly by theca and granulosa cells (25\%), the adrenal zona fasciculata (25\%), and from circulating androstenedione $(50 \%)[11,12]$. Peripheral tissues such as placenta, liver, skin, prostate, and adipose tissue possess the specific enzymes (or the isoforms) required for the novo synthesis of androgens or their activation from circulating precursors [13]. Furthermore, in the vascular smooth muscle (VSM), airway smooth muscle (ASM), and heart (the tissues that this review is focused on), the expression of some steroidogenic enzymes has been demonstrated. For instance, CYP11A1 and $3 \beta$-HSD are expressed in cardiac $[14,15]$, vascular [15, 16], and lung tissue [17]. Nevertheless, CYP17A1, which is required for the conversion of pregnenolone into 17-hydroxypregnenolone, was not found in the heart $[14,15]$, and it has not been reported in vascular or ASM. Therefore, de novo androgen biosynthesis is unlikely to occur in those tissues. However, the expression of $17 \beta$ HSD5 in the fetal lung $[18,19]$ and $17 \beta$-HSD1,2 in the heart [20] can lead to the biotransformation of pre-existing precursors to T. Interestingly, no significant expression of $17 \beta$-HSD3 was found in the heart and the lung since this enzyme is considered to be testis-specific [21]. Furthermore, the presence of $5 \alpha$-reductase in the cardiac tissue allows the formation of $5 \alpha$-DHT [20]. Additionally, P450aro has been found in vascular tissues [22, 23], heart [20], and lung epithelial cells [24].

Men usually have much higher levels of T serum concentrations than women. In men from 13 to 80 years old, values of serum $\mathrm{T}$ are between 6 and $50 \mathrm{nM}$ [25-27]. $5 \alpha$ DHT (a more potent androgen) represents about $9-10 \%$ of the plasma $T$ levels in males of most species $[26,28]$. In women, stable serum values of $\mathrm{T}(0.7-2.5 \mathrm{nM})$ are maintained except during pregnancy when $\mathrm{T}$ concentrations increment $(3.5-5 \mathrm{nM})$ [27]. Also, $5 \alpha$-DHT is essentially produced in peripheral tissues and circulates in very low concentrations in women plasma $(0.069 \mathrm{nM})$ [29].

1.2. Nongenomic and Genomic Actions of Androgens. The androgen signaling comprises nongenomic and genomic pathways. The nongenomic effects of androgens are independent of the binding to the cytosolic AR and occur in seconds to minutes [30]. Importantly, these effects are not altered by inhibitors of transcription and seem to be carried out by the androgen binding to plasma membrane lipids or ionic channels [2,31-35]. Recently, two distinct membrane proteins have been suggested as membrane androgen receptors (mARs): $\mathrm{G}$ protein-coupled receptor family $\mathrm{C}$ group 6-member A (GPRC6A) and zinc-regulated transporter [Zrt]-protein 9 (ZIP9); both of them may stimulate intracellular pathways via $G$ proteins or mitogen-activated protein kinases (MAPKs) [31, 36-38].

GPRC6A is a member of the $C$ family of $G$ proteincoupled receptors (GPCRs) activated by several ligands such as extracellular $\mathrm{Ca}^{2+}$, cations, basic amino acids, osteocalcin, and $\mathrm{T}$ [31, 39-41]. Pi et al. in 2010 showed that the stimulation of GPRC6A triggers the inhibitory G protein $\alpha$-subunit (G $\alpha \mathrm{i})$, phosphatidylinositol 3-kinase (PI3K), protein kinase C (PKC), proto-oncogene c-Src kinase (Src), and Ras/Raf/mitogen-activated protein kinase kinase (MEK)/extracellular signal-regulated kinase (ERK) signaling pathways [42]. Most recently, the same authors reported that the activation of GPRC6A by testosterone induces cell proliferation and inhibits autophagy through the mammalian target of the rapamycin complex 1 (mTORC1) signaling cascade in prostate cancer cells [43]. ZIP9 is a protein that possesses seven membrane-spanning domains and was first identified as a member of the SLC39A zinc transporter family in Atlantic croaker ovaries [44]. The stimulation of ZIP9 leads to the activation of the Gq protein $\alpha$-subunit (Gq11) in spermatogenic cells, the stimulatory G protein $\alpha$-subunit $(\mathrm{G} \alpha \mathrm{s})$ in ovarian follicle cells, and the inhibitory $\mathrm{G}$ protein $\alpha$-subunit ( $\mathrm{G} \alpha \mathrm{i})$ in prostate cancer cells [36, 37, 44]. Moreover, the activity of ZIP9 (dependent on T stimulation) has also been explored in a Sertoli cell line, where this receptor modulates the phosphorylation of ERK1/2 [45]. While the MAPKs signaling pathway can lead to transcription modulation [46], the role of the mARs in the physiology of cardiac and smooth muscle cells is still unrevealed.

The genomic effects of $\mathrm{T}$ occur from hours to days and involve the binding of the androgen to a cytosolic androgen receptor (AR). This hormone receptor, also known as NR3C4, is a member of the nuclear receptor family [47, 48]. As in other nuclear receptors, the protein structure of the AR comprises the $\mathrm{N}$-terminal domain (NTD), the DNA-binding domain (DBD), the hinge domain (HD), and the ligandbinding domain (LBD) [49]. The stimulation of the AR by T or $5 \alpha$-DHT elicits the dissociation of chaperone proteins and the formation of a complex that is transferred to the nucleus where it modulates gene transcription and protein synthesis [2]. $5 \beta$-DHT, the other reduced metabolite of $\mathrm{T}$, possesses minor androgenic activity due to a lower binding affinity than $5 \alpha$-DHT [50]. The AR is expressed in several mammalian tissues, including vascular and airway smooth muscles and cardiac myocytes [2, 51-56]. Furthermore, the activity of the AR has been implicated in cardiovascular and respiratory ailments such as vascular ischemia [53], hypertension [57, 58], asthma [52], and cardiac hypertrophy [54].

In the last years, numerous AR splice variants have been molecularly identified and characterized in humans. Although the function of these alternative AR transcripts in the human physiology is not completely understood, these variants have been related to pathological conditions such as prostate cancer $(\mathrm{PCa})$ and androgen insensitivity syndrome (AIS) [59-62]. In 2005, Ahrens-Fath et al. reported the existence of an NTD-truncated AR isoform with a molecular weight of $45 \mathrm{kDa}$ (AR45) in the heart, skeletal muscle, uterus, prostate, breast, and lung [63]. However, the expression level of AR45 compared with the wild-type AR in these tissues is arguable since a semiquantitative RT-PCR was performed by Ahrens-Fath et al. Also, this receptor variant is expressed in 


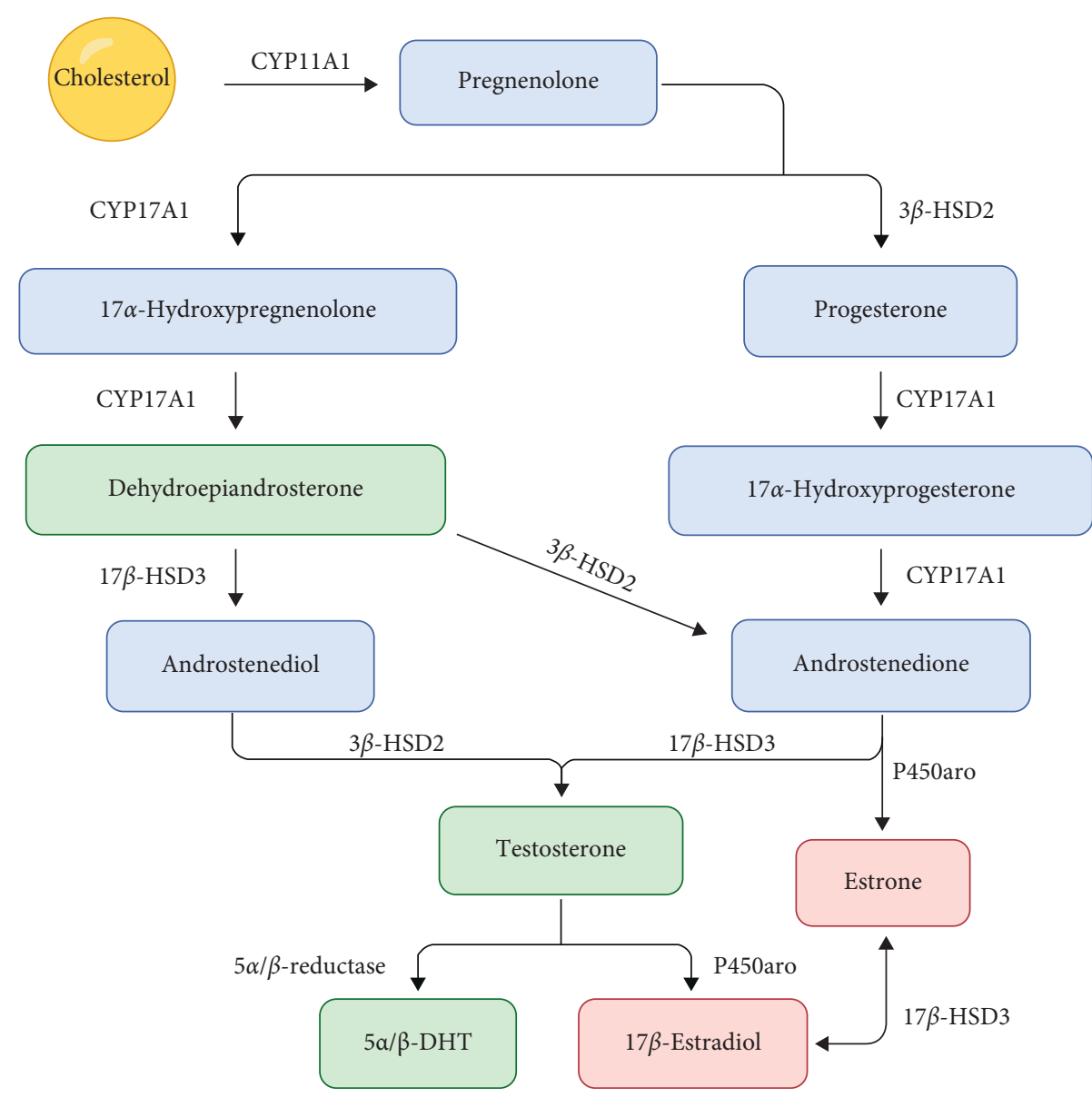

FIGURE 1: Androgen synthesis from cholesterol. Steroidogenesis in males is carried out mainly by Leydig cells and in females by theca and granulosa cells. Cholesterol is the precursor of all sex steroids, and its conversion to pregnenolone is mediated by the cholesterol side-chain cleavage cytochrome P450 enzyme (CYP11A1/P450scc). Once formed, this progestogen is converted into progesterone by $3 \beta$-hydroxysteroid dehydrogenase (3 $\beta$-HSD2). Then, $17 \alpha$-hydroxylase/17,20 lyase (CYP17A1/P450c17) hydroxylates pregnenolone to produce $17 \alpha$ hydroxypregnenolone and subsequently removes the acetyl group to form dehydroepiandrosterone (DHEA). This last product can be either converted into androstenedione via $3 \beta$-HSD2 or into androstenediol by $17 \beta$-hydroxysteroid dehydrogenase (17 $\beta$-HSD3). Androstenedione and androstenediol are further biotransformed to testosterone by $17 \beta-$ HSD 3 and $3 \beta$-HSD2, respectively. Furthermore, testosterone can be reduced to $5 \alpha$ - or $5 \beta$-dihydrotestosterone $(5-\alpha / \beta$-DHT) by 5 - $\alpha / \beta$-reductases. Furthermore, $\mathrm{P} 450$ aromatase (P450aro) may convert testosterone into $17 \beta$-estradiol and androstenedione into estrone. Finally, $17 \beta$-HSD3 catalyzes the formation of $17 \beta$-estradiol from estrone.

the normal prostate tissue and in human prostate adenocarcinoma derived from the left supraclavicular lymph node metastasis (LNCaP) cells $[64,65]$. Additionally, it has been shown that AR45 may repress or stimulate wild-type AR activity [63]. Interestingly, $12 \mathrm{AR}$ variants lacking the LBD (ARV1-12) have been identified in PCa cell lines [64-67]. Among all the ARV isoforms, ARV7 (also known as AR3) has gained relevance due to its demonstrated capability of mediating constitutively AR functions, i.e., constitutive gene transcription in the absence of androgen stimuli. Moreover, ARV7 has been suggested as a predictive biomarker in castrate-resistant $\mathrm{PCa}$ since it promotes cancer progression and androgen depletion-resistant growth by regulating serine/threonine kinase 1 encoding gene (AKT1) [64-67]. In spite of the emerging evidence about AR splice variants, further studies are imperative in order to elucidate the possible expression and the physiological role of these alternative transcripts in vascular and airway smooth muscles and cardiac muscle.

Noteworthy, it has been proposed that androgen nongenomic and genomic actions may converge. For instance, in the vascular smooth muscle, the regulation of $\mathrm{K}^{+}$channels is dependent on nongenomic and genomic effects of androgens [30]; however, cellular mechanisms and signaling pathways displayed in both types of actions are entirely different and carried out by distinct effector proteins.

1.3. Androgens and Vascular, Airway, and Cardiac Muscles. Vascular smooth muscle (VSM), airway smooth muscle (ASM), and cardiac muscle (CM) cells are excitable entities, with the primary function of contracting and relaxing [68]. Several research groups have shown that androgens interact with the contraction and relaxation mechanisms of different 
muscular cell types from distinct species through nongenomic and genomic effects.

With respect to nongenomic actions, in the VSM, numerous authors have reported that androgens induced vasorelaxation in different arteries [69-74]. In this regard, in the ASM, our group and others have observed that DHEA, T, $5 \alpha$-DHT, and $5 \beta$-DHT induced-relaxation through nongenomic actions [33, 75-78].

In relation to the genomic actions, it has been reported that $\mathrm{T}$ and DHT induced in the VSM, the genic expression of proteins such as adenylyl cyclase (AC), $\mathrm{Ca}^{2+}$-activated $\mathrm{K}^{+}$ channels of high conductance $\left(\mathrm{BK}_{\mathrm{Ca}}\right)$, and L-type voltagedependent $\mathrm{Ca}^{2+}$ channels (L-VDCCs) [73, 79]. Most recently, we found in the ASM that T augmented the expression of $\beta_{2}$-ARs, favoring an increase in the relaxing response to salbutamol [51]. In the CM, it has been described that androgens (via a genomic effect) increased the expression of the voltage-dependent delayed rectifier $\mathrm{K}^{+}$ channel $1.5\left(\mathrm{~K}_{\mathrm{V}} 1.5\right)$, leading to shortening of the action potential duration in mice ventricular cardiomyocytes [80], and also enhanced the expression of $\mathrm{K}_{\mathrm{V}} 1.7$ diminishing the QT intervals in rats [81]. Testosterone nongenomic and genomic actions and their association with the adrenergic system of vascular, airway, and cardiac myocytes are discussed in the next sections of this manuscript.

1.4. Adrenergic Receptors in Vascular, Airway, and Cardiac Muscles. Under physiological conditions, the adrenergic system plays a critical role in regulating vascular, airway, and cardiac function. In the VSM and CM, sympathetic innervation modulates contraction [82] and the intrinsic conduction system $[83,84]$, respectively. The ASM tone is partly regulated through circulating catecholamines such as epinephrine released from the adrenal medulla $[85,86]$; this hormone acts as an adrenergic receptor agonist. The adrenergic receptors or adrenoceptors are members of the superfamily of G protein-coupled receptors (GPCRs) and modulate several pathways through effectors such as AC or phospholipase C (PLC) [87]. Adrenergic receptors have been classified into three major categories: alpha-1-adrenergic receptors $\left(\alpha_{1}\right.$-ARs), alpha-2-adrenergic receptors $\left(\alpha_{2}\right.$-ARs), and beta-adrenergic receptors ( $\beta$-ARs). Moreover, each of these groups has been further subclassified into multiple subtypes defined by the differences in their genetic sequences and their pharmacological action: $\alpha_{1 \mathrm{~A}}, \alpha_{1 \mathrm{~B}}, \alpha_{1 \mathrm{D}}, \alpha_{2 \mathrm{~A}}$, $\alpha_{2 \mathrm{~B}}, \alpha_{2 \mathrm{C}}, \beta_{1}, \beta_{2}$, and $\beta_{3}[88,89]$.

$\alpha_{1}$-ARs are coupled to a heterotrimeric Gq protein and PLC signaling pathway. PLC triggers the formation of inositol 1,4,5-trisphosphate $\left(\mathrm{IP}_{3}\right)$ and diacylglycerol (DAG), resulting in the increase of the intracellular $\mathrm{Ca}^{2+}$ concentration $\left(\left[\mathrm{Ca}^{2+}\right]_{\mathrm{i}}\right)$ and the activation of protein kinase $\mathrm{C}$ (PKC) [87, 90-92]. Also, the stimulation of $\alpha_{1}$-ARs promotes an extracellular $\mathrm{Ca}^{2+}$ influx through voltage-dependent $\mathrm{Ca}^{2+}$ channels (VDCCs) [93] and triggers extracellular signalregulated kinases 1 and 2 (ERK1/2) [94, 95]. In humans, $\alpha_{1 \mathrm{~A}}$, $\alpha_{1 \mathrm{~B}}$, and $\alpha_{1 \mathrm{D}}$ adrenergic receptors are encoded by distinct genes located on chromosomes 8,5 , and 10 , respectively [87]. The three subtypes of $\alpha_{1}$-ARs are present in most blood vessels modulating smooth muscle contraction and vascular tone. $\alpha_{1 \mathrm{~A}}$ is the most prevalent subtype in human arteries; nevertheless, the expression levels of $\alpha_{1}$-ARs depend on the vascular bed studied. $\alpha_{1 \mathrm{D}}$-AR subtype predominates in large conduction vessels as the aorta and carotid arteries, whereas $\alpha_{1 \mathrm{~A}}-\mathrm{AR}$ subtype is involved in regulating vascular tone of mesenteric, splenic, pulmonary, and caudal (in mice and rats) arteries controlling organ blood flow [96-101]. While $\alpha_{1 \mathrm{~A}}$ and $\alpha_{1 \mathrm{D}}$-ARs are the main subtypes involved in vascular contractions, $\alpha_{1 \mathrm{~B}}-\mathrm{AR}$ subtype is also expressed in several blood vessels, and it was thought that it did not require extracellular $\mathrm{Ca}^{2+}$ to activate smooth muscle contraction $[99,100]$. Unfortunately, studies related to $\alpha_{1 \mathrm{~B}}$-AR function in the VSM have been restrained by the lack of selective antagonists. However, this receptor subtype has been proposed to be involved in the regulation of systemic BP [102-104] and coronary blood flow [105].

The evidence of $\alpha$-ARs in the ASM is also present; nonetheless, these receptors seem not to be relevant in the functionality of this tissue. In this context, norepinephrineinduced contraction has been observed in guinea pig $[106,107]$, rabbit, cat, and rat [107] tracheal preparations but only after $\beta$-AR blockade. Interestingly, Kneussl and Richardson in 1978 found that human and dog ASM did not contract in response to norepinephrine, unless they were previously stimulated with histamine or $\mathrm{KCl}$ [108]. These insights confirm the predominance of relaxant $\beta$-AR function in the ASM of most mammals. However, in 1985, Montaño et al. revealed that the Erythrocebus patas monkey possesses $\alpha$-AR predominance in this tissue [109].

In cardiomyocytes of species such as mice, rats, and humans, all three $\alpha_{1}$-AR mRNAs have been detected with the predominance of $\alpha_{1 \mathrm{~A}^{-}}$and $\alpha_{1 \mathrm{~B}^{-}} \mathrm{AR}$ subtypes $[105,110-112]$. Although the stimulation of these receptors in cardiomyocytes can evoke muscle contraction, most works have been focused only on ventricular heart sections. In this context, it has been observed that norepinephrine and epinephrine can induce positive inotropic and chronotropic effects in the right atrium from mice, probably through $\alpha_{1^{-}}$ AR signaling [113]. Nevertheless, different studies have shown that, in the heart, $\alpha_{1}$-ARs are mainly involved in processes such as hypertrophic responses, upregulation of myosin light chain-2, modulation of the atrial natriuretic factor (ANF), and heart failure [114-120].

$\alpha_{2 \mathrm{~A}}, \alpha_{2 \mathrm{~B}}$, and $\alpha_{2 \mathrm{C}}$ adrenoceptor genes are located on human chromosomes 10, 4, and 2, respectively. The encoded products share about $50 \%$ of amino acid identity and show the same affinity for norepinephrine and epinephrine [121]. All $\alpha_{2}$-ARs are coupled to the pertussis toxin-sensitive G proteins such as Gi/Go and to the inhibition of the AC. The consequence of the inhibition of this enzyme is a decrease in the production $3^{\prime}, 5^{\prime}$-cyclic adenosine monophosphate (cAMP), reducing the activity of protein kinase A (PKA) [121-125]. Additionally, Gi/Go signaling cascade modulates $\mathrm{Ca}^{2+}[126,127]$ and $\mathrm{K}^{+}[128,129]$ channels without the involvement of other second messengers. VSM cells express all subtypes of $\alpha_{2}$-ARs, and their stimulation is related to contraction and vasopressor effects [124, 130-132]. $\alpha_{2 \mathrm{~A}^{-}}$ Adrenoceptor is the most predominant subtype in this tissue 
and participates in the regulation of the muscular tone in the aorta [133] and carotid (possibly controlling cerebral blood flow) $[134,135]$ and mesenteric arteries [136] and in the peripheral vasoconstriction related to the skin blood flow [137]. $\alpha_{2 \mathrm{~B}}-\mathrm{AR}$ is more involved in the vascular tone of smaller arteries [138] but contributes to BP regulation to a greater extent than $\alpha_{2 \mathrm{~A}^{-}}$and $\alpha_{2 \mathrm{C}^{-}}$ARs [139]. Furthermore, $\alpha_{2}$-adrenoceptors seem to play a minor role in cardiac contractility compared to $\beta$ - and $\alpha_{1}$-ARs. Recently, it was demonstrated in ventricular cardiomyocytes that the stimulation of $\alpha_{2}$-ARs could modify $\left[\mathrm{Ca}^{2+}\right]_{\mathrm{i}}$ and induce myocardial contraction [140, 141].

$\beta$-ARs, like all other adrenergic receptor subtypes, are composed of seven transmembrane spanning helices. The three subtypes $\left(\beta_{1}, \beta_{2}\right.$, and $\left.\beta_{3}\right)$ are found in VSM [87], ASM [142], and CM [143] cells. Their coding genes are located in human chromosomes 10,5 , and 8 , respectively $[87,144,145]$. The stimulation of the $\beta$-AR mediates the activation of $\mathrm{AC}$ and the subsequent increment in the production of cAMP $[146,147]$. In its active state, $\beta$-AR is associated with the $\alpha$-subunit of Gs protein. In the VSM, the activation of $\beta$-ARs induces the relaxation of the tissue, regulating the peripheral vascular resistance and controlling the organ blood flow and vascular tone [87]. Among all $\beta$-ARs, $\beta_{2}$-AR is the predominant expressed subtype in most vascular beds, while a minor proportion of $\beta_{1}$-ARs is also present. Apparently, $\beta_{1}$-adrenoceptors play an essential role in the function of coronary and cerebral arteries $[87,148-151]$. $\beta$-Adrenoceptors also occur in endothelial cells where they mediate vasodilation through nitric oxide (NO) production [152]. In airways, $\beta_{2}$-agonists are well known as the most effective bronchodilators. The $\beta_{2}$-agonist binding to the $\beta_{2}-\mathrm{AR}$ in the cell membrane of the ASM triggers the formation of cAMP by the action of the AC [153-155]. Subsequently, the increment of the cAMP levels activates PKA, a phosphorylating protein, which favors $\mathrm{K}^{+}$ channel opening and bronchorelaxation [156]. In the heart, $\beta_{1}$ and $\beta_{2}$ are the most valuable adrenoceptor subtypes with a predominance of $\beta_{1}$-ARs over $\beta_{2}$-ARs (ratio of $\sim 80 / 20$ ). The stimulation of these receptors in cardiomyocytes mediates positive chronotropic, inotropic, and lusitropic effects [157-159]. Gs-PKA signaling in cardiomyocytes promotes the phosphorylation of phospholamban (PLB), L-VDCCs, ryanodine receptors (RyRs), and cardiac myosin-binding protein $\mathrm{C}$ leading to an increase in $\left[\mathrm{Ca}^{2+}\right]_{\mathrm{i}}$ and favoring muscle contraction [160]. Interestingly, it has been demonstrated that a sustained activation of $\beta_{1}$-ARs may induce cardiotoxic effects, and $\beta_{2}$-ARs switch their natural Gs coupling to Gi protein coupling, opposing the positive $\beta_{1}$ AR effects [157, 161, 162].

It is well known that adrenoceptors play a key role in maintaining vascular, airway, and cardiac muscular function. In this regard, the modulation by $\mathrm{T}$ of the adrenergic receptor signaling pathway has been investigated, and the observed effects appear to be dependent on the studied tissue and the predominance of the adrenergic receptor subtypes either favoring muscle relaxation or contraction $[51,79,163,164]$. This review focuses on the effects of $\mathrm{T}$ on the adrenergic system in the vascular, airway, and cardiac muscles and its relevance in pathological processes related to this system.

\section{Vascular Smooth Muscle}

The maintenance of the vascular tone is due to the balance between vasoconstriction and vasorelaxation modulated by several neurotransmitters and hormones [165]. The VSM found in the medial layer of the blood vessels is responsible for controlling vascular tone and blood pressure (BP) [166]. The regulation of the VSM membrane potential and the vascular tone is mainly determined by $\mathrm{Ca}^{2+}$ and $\mathrm{K}^{+}$channels $[167,168]$. The main $\mathrm{K}^{+}$channels expressed in the VSM are the voltage-dependent delayed rectifier $\mathrm{K}^{+}$channels $\left(\mathrm{K}_{\mathrm{V}}\right)$, $\mathrm{Ca}^{2+}$-activated $\mathrm{K}^{+}$channels of high conductance $\left(\mathrm{BK}_{\mathrm{Ca}}\right)$, ATP-sensitive $\mathrm{K}^{+}$channels $\left(\mathrm{K}_{\mathrm{ATP}}\right)$, and inward-rectifier $\mathrm{K}^{+}$ channels $\left(K_{I R}\right)[169,170]$. VSM constriction is caused by increments in $\left[\mathrm{Ca}^{2+}\right]_{i}[171]$. Vasoconstrictor agonists act on GPCRs coupled to the ${ }_{\mathrm{q}} \alpha$ subunit (GPCR-${ }_{\mathrm{q}} \alpha$ ) such as $\alpha_{1 \mathrm{~A}^{-}}$, $\alpha_{1 \mathrm{~B}^{-}}$, and $\alpha_{1 \mathrm{D}^{-}}$ARs, bradykinin, histamine $\mathrm{H}_{1}$, and thromboxane- $\mathrm{A}_{2}$ receptors, among others [172-174]. These receptors activate the PLC enzyme and $\mathrm{IP}_{3}$ signaling pathway, inducing the release of $\mathrm{Ca}^{2+}$ from the sarcoplasmic reticulum (SR) and the influx of this ion through VDCCs [175]. In the VSM, two major subtypes of VDCCs with distinct electrophysiological properties are present. L-VDCCs are activated by large depolarizations and inactivated relatively slowly. T-type voltage-dependent $\mathrm{Ca}^{2+}$ channels (T-VDCCs) are activated by small depolarizations and inactivated rapidly $[176,177]$.

Moreover, VDCCs are not the only source of extracellular $\mathrm{Ca}^{2+}$. The influx of this ion is also carried out by nonselective cation channels such as receptor-operated $\mathrm{Ca}^{2+}$ channels (ROCCs), store-operated $\mathrm{Ca}^{2+}$ channels (SOCCs), and transient receptor potential (TRP) channels. The $\mathrm{Ca}^{2+}$ influx exerted by these channels is thought to be triggered by agonists such as norepinephrine, vasopressin, and acetylcholine via GPCRs linked to the phospholipase $\mathrm{C}_{\beta}\left(\mathrm{PLC}_{\beta}\right)$ signaling pathway and the formation of $\mathrm{IP}_{3}$ and DAG. This last second messenger regulates the activity of ROCCs, and $\mathrm{IP}_{3}$ induces depletion of internal $\mathrm{Ca}^{2+}$ stores leading to capacitative $\mathrm{Ca}^{2+}$ entry through SOCCs [178-181]. Additionally, TRP channels have been classified as ROCC subtypes, and transient receptor potential canonical channels 3 , 6, and 7 (TRPC3, TRPC6, and TRPC7) have been shown to be susceptible to DAG stimulation promoting its opening and contributing to $\mathrm{Ca}^{2+}$ influx. Afterward, $\mathrm{Ca}^{2+}$ complexes with calmodulin to activate myosin light-chain kinase (MLCK) causing vasoconstriction [168, 182]. Conversely, the decrease in cytosolic $\mathrm{Ca}^{2+}$ leads to vasorelaxation [183]. Vasodilator agonists that stimulate GPCRs coupled to the ${ }_{s} \alpha$ subunit (GPCR- ${ }_{s} \alpha$ ) such as $\beta_{1^{-}}$and $\beta_{2}$-ARs, histamine $\mathrm{H}_{2}$, prostaglandin $\mathrm{E}_{2}$, and adenosine $\mathrm{A}_{2}$ receptors, among others [184], induce the synthesis of cAMP and $3^{\prime}, 5^{\prime}$-cyclic guanosine monophosphate (cGMP); therefore, they activate PKA and protein kinase G (PKG), respectively [185], leading to a decrease in the vascular tone [183]. In the last two decades, the evidence about the relationship between androgens and vascular reactivity has increased. The 
nongenomic effects of T in the VSM can be due to its action on ion channels resulting in vasorelaxation. In 1996, Perusquía et al. postulated that T, $5 \beta$-DHT, and $5 \alpha$-DHT induced vasorelaxation in the rat aorta [186]. Later on, the same group observed that $\mathrm{T}$ was capable of blocking the extracellular $\mathrm{Ca}^{2+}$ influx inducing vasorelaxation of the precontracted human umbilical artery [72]. More recently, it was demonstrated that $5 \beta$-DHT and $\mathrm{T}$ induced vasorelaxation by blocking L-VDCCs in the rat thoracic aorta [70]. In addition to blocking $\mathrm{Ca}^{2+}$ entry through $\mathrm{L}$-type $\mathrm{Ca}^{2+}$ channels, $\mathrm{T}$ is capable of activating $\mathrm{K}^{+}$channels. The efflux of $\mathrm{K}^{+}$evokes membrane hyperpolarization and closes $\mathrm{Ca}^{2+}$ channels leading to vasorelaxation in pig [187] and rabbit [188] coronary arteries. In this regard, different types of $\mathrm{K}^{+}$ channels have been proposed as targets for $\mathrm{T}$ modulation. In the dog coronary artery [189] and rat aorta [190], $\mathrm{K}_{\mathrm{ATP}}$ channels have been shown to be involved in the T-associated relaxant effect. $\mathrm{BK}_{\mathrm{Ca}}$ channel activation in the human internal mammary artery [191] and pig coronary artery [187] is also implicated in T-induced vasorelaxation. Moreover, Saldanha et al. demonstrated that $\mathrm{T}$ produced relaxant responses in human umbilical artery rings precontracted with serotonin (5-HT), histamine, and $\mathrm{KCl}$, and these effects were dependent on both $\mathrm{BK}_{\mathrm{Ca}}$ and $\mathrm{K}_{\mathrm{V}}$ channel activity (Figure 2(a)). They also studied the long-term effects of androgens in the same model, founding that DHT, through genomic actions, decreased the mRNA expression of the $\alpha$-subunit of L-VDCC and upregulated the $\beta_{1}$-subunit of $\mathrm{BK}_{\mathrm{Ca}}$, favoring relaxation [73].

\subsection{The Effects of Testosterone on Adrenergic Receptors in the} Vascular Smooth Muscle. Sex differences in cardiovascular diseases, i.e., hypertension, have been broadly studied. Men are more likely to develop hypertension or coronary heart disease (CHD) than women [192-194]. Hypertension is defined as persistent systolic $\mathrm{BP} \geq 140 \mathrm{mmHg}$ and or diastolic $\mathrm{BP} \geq 90 \mathrm{mmHg}$, according to $2018 \mathrm{ESC} / \mathrm{ESH}$ guidelines [195]. The World Health Organization has rated hypertension as one of the deadliest causes of premature death worldwide due to its asymptomatic behavior that can result in concomitant diseases after years. In this regard, sex differences in the development of hypertension have been reported. Female sex hormones, such as estrogens, have been widely implicated in the hypertension-related gender differences [57]; however, several authors have pointed out a prohypertensive role for androgens [58]. Studies in humans and castrated rats revealed that androgens exert a prohypertensive effect, while estrogens appear to oppose the increase in BP [196]. In this context, Torres et al. found in castrated male Wistar rats an increment in aortic vasodilation, indicating a sex hormone influence [197]. Another research group observed that gonadectomized hypertensive rats, both males and females, showed a reduced $\mathrm{BP}$, and the administration of $\mathrm{T}$ restored it in the castrated male experimental group [198]. Moreover, it has been proposed that the effect of T on VSM does not benefit a state of relaxation but rather favors vasoconstriction. Fluctuations in androgen concentrations throughout life stages can affect the vascular tone, and T may contribute to developing hypertension [58]. In this sense, hyperandrogenism (HA) in pre- and postmenopausal women has been associated with an unfavorable metabolic profile, obesity, and hypertension [199-201]. HA is defined as an excess of androgen production and secretion by adrenal glands or the ovaries [202]. Moreover, the development of HA in females has shown to be associated with ovarian disorders, e.g., ovarian hyperthecosis (OH) [203], virilizing ovarian tumors (VOTs) [204], and polycystic ovary syndrome (PCOS) [199-201]. PCOS is one of the most common endocrine disorders affecting women of reproductive age [205]. The metabolic phenotype in PCOS is characterized by increased LH compared with the folliclestimulating hormone (FSH) and HA [205, 206]. Furthermore, evidence points out that hyperandrogenemia in women suffering from PCOS is associated with an increased systolic and diastolic BP, and this relation is independent of other risk factors such as obesity and insulin resistance [207].

During aging, the vascular tone is led to vasoconstriction, and $\beta$-ARs have been proposed as targets of several drugs related to hypertension disease [208]. Aged animals have a weak vascular response to $\beta$-AR agonists, and possibly, mechanisms of the $\beta$-AR signaling pathway are altered [209]. Vascular tone is modulated through the action of the sympathetic nervous system (SNS) on $\beta$-ARs promoting the increase in cAMP levels $[142,210]$. It has been reported that androgens promote vasoconstriction by increasing catecholamine (mainly norepinephrine) levels [57]. In 2005, Martin et al. demonstrated that the adrenergic system (through norepinephrine action) reduced the mean arterial pressure in castrated male spontaneously hypertensive rats (SHR) [211]. In other studies, vascular tone at different stages of rat growth was compared to explore the role of T in $\beta$-adrenergic-induced vasodilation [79]. In aortic rings of mature rats, vasorelaxation response induced by isoproterenol (a well-known unspecific $\beta$-adrenergic agonist) showed an impairment of this response compared to aortic rings obtained from younger rats. According to the authors, this impaired relaxing response could be related to higher plasma T-levels in older rats. The authors elegantly demonstrated that $\mathrm{T}$ reduced the $\beta$-AR-elicited vasorelaxation without any alteration in the expression of the $\beta_{2}$-AR but interfering downstream in the signaling cascade. Furthermore, the authors exhibited that $\mathrm{T}$ (via a genomic effect) diminished the expression of AC and yielding of cAMP in castrated rats [79]. These findings point out that changes in the levels of T could lead to high BP and hypertension.

Furthermore, the vessel tone is also regulated by $\alpha$-ARs. These receptors promote vasoconstriction and might contribute to hypertension development [92]. In this context, the modulation of the $\alpha_{1}$-AR by $\mathrm{T}$ has been reported. Testosterone replacement therapy increased BP in gonadectomized SHR and the number of $\alpha_{1}$-ARs in the tail artery [164]. Furthermore, in 1999, it was found that the incubation for $24 \mathrm{hr}$ with $\mathrm{T}(0.1 \mathrm{nM}-1 \mu \mathrm{M})$ increased the abundance of $\alpha_{1 \mathrm{~B}}$-AR mRNA in VSM cells through a genomic action. The same study reported that glucocorticoids, such as dexamethasone, increased catecholamine-mediated 


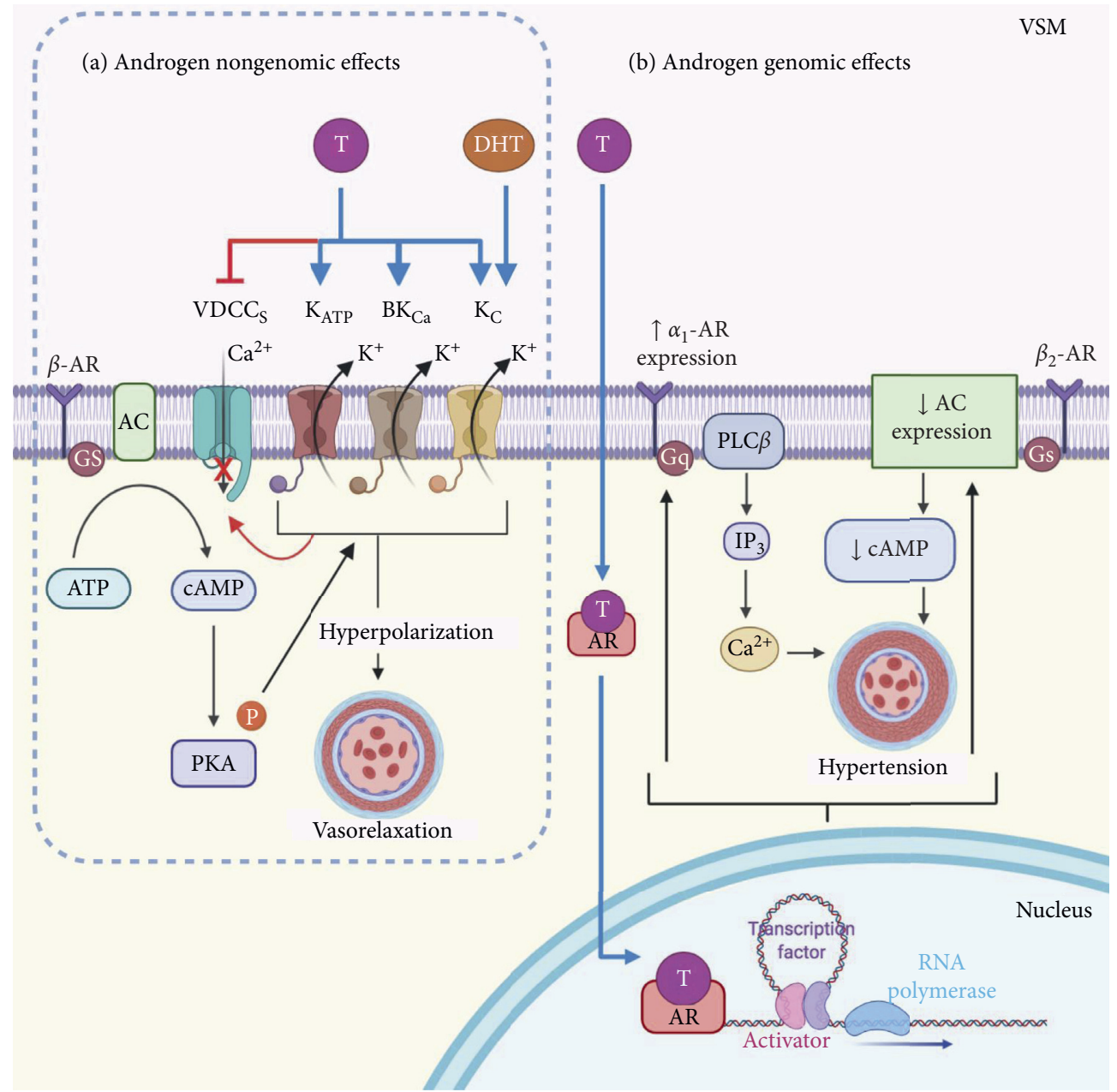

FIgURE 2: Androgen effects on the adrenergic system in the vascular smooth muscle (VSM). (a) Stimulation of the $\beta$-adrenergic receptor $(\beta-\mathrm{AR})$ leads to an increase in the activity of the $\mathrm{K}^{+}$channels and to plasma membrane hyperpolarization. $\beta$-AR receptor is coupled to a Gs protein (Gs) that activates adenylyl cyclase (AC), which enhances the synthesis of $3^{\prime}, 5^{\prime}$-cyclic adenosine monophosphate (cAMP) and consequently promotes the protein kinase A- (PKA-) induced phosphorylation of the $\mathrm{K}^{+}$channels. $\mathrm{K}^{+}$channel phosphorylation increases their open probability and evokes membrane hyperpolarization that closes $\mathrm{Ca}^{2+}$ channels, leading to vasorelaxation. Testosterone, via a rapid response (nongenomic), activates $\mathrm{ATP}$-sensitive $\mathrm{K}^{+}$channels $\left(\mathrm{K}_{\mathrm{ATP}}\right), \mathrm{Ca}^{2+}$-activated $\mathrm{K}^{+}$channels of high conductance $\left(\mathrm{BK}_{\mathrm{Ca}}\right)$, and voltage-dependent delayed rectifier $\mathrm{K}^{+}$channels $\left(\mathrm{K}_{\mathrm{V}}\right)$. Dihydrotestosterone (DHT, a reduced metabolite of $\mathrm{T}$ ) enhances the activity of the $\mathrm{K}_{\mathrm{V}}$ channel. T also blocks VDCCs. Androgen-induced vasorelaxation mediated by the activation of $\mathrm{K}^{+}$channels and the blockade of VDCCs might improve the response of $\beta$-AR signaling. (b) The genomic androgen receptor (AR) signaling involves androgen crossing the plasma membrane, entering the cytoplasm, dissociation of chaperone proteins, and binding to its cytosolic receptor. AR stimulation by T results in a decrement of AC expression and a reduction of cAMP synthesis. Moreover, Tincreases the $\alpha_{1}$-adrenergic receptor $\left(\alpha_{1}\right.$-AR) expression. This receptor is coupled to a $\mathrm{Gq}$ protein $(\mathrm{Gq})$, which, through phospholipase $\mathrm{C}_{\beta}\left(\mathrm{PLC}_{\beta}\right)$, catalyzes the formation of inositol-1, 4, 5-triphosphate $\left(\mathrm{IP}_{3}\right)$ and triggers intracellular calcium release from the sarcoplasmic reticulum (SR). The genomic effects of T favor vasoconstriction in the VSM and might lead to hypertension development.

vasoconstriction due to an increased $\alpha_{1 \mathrm{~B}} \mathrm{AR}$ expression [212]. In this context, $\mathrm{T}$ is not the only steroid hormone related to vascular physiology. High concentrations of glucocorticoids (such as cortisol) promote the retention of sodium and decrease the activity of prostaglandins leading to a contracted state of the VSM [213].

Although the regulation through norepinephrine of the vessel tone is essential for both females and males, the existence of sex differences in vessel vasoconstriction and vasodilatation has been reported. In 2017, Al-Gburi et al. demonstrated that the $\alpha$-adrenergic vasoconstriction was weaker in female than male rats. They also found that the stimulation of $\beta_{1^{-}}, \beta_{2^{-}}$, and $\beta_{3^{-}}$-ARs evoked a greater response of relaxation in females than in males [214]. The diminished vasoconstriction and the enhanced vasorelaxation were due to the upregulated expression of the $\beta_{1}$ - and $\beta_{3}$-ARs mainly in an endothelial location in female rats. Later on, Riedel et al. confirmed the overexpression of the $\beta_{1^{-}}$and $\beta_{3}$-ARs in endothelial cells of the blood vessel by the action of the estrogens. The endothelial adrenergic stimulation caused an enhanced NO-dependent vasorelaxation in female rats [215], counteracting the vasoconstrictive outcomes 
modulated by the $\alpha$-ARs [215]. These findings could explain very well the sex and age differences on the role of the adrenergic response in the VSM.

In conclusion, $\mathbf{T}$ reduces the $\beta$-AR-elicited vasorelaxation by interfering downstream in the signaling pathway and upregulates the $\alpha$-AR expression (Figure 2(b)). These hormonal effects are carried out principally through genomic actions leading to vasoconstriction and might be involved in the development of hypertension. Nevertheless, androgen nongenomic actions have opposite outcomes in the VSM, yielding their effects to vasorelaxation. However, the genomic actions of androgens (long-term effects) seem to be the predominate deleterious effects favoring hypertension. Therefore, the possible use of androgens, due to their nongenomic actions, as a therapeutic tool for the treatment of hypertension could not be appropriated based on their long-term genomic actions.

\section{Airway Smooth Muscle}

The maintenance of proper air flux through the airways results from the balance between contraction and relaxation of the ASM. The response of the ASM to physiological and pathophysiological stimuli determines the airway caliber in order to regulate the airflow [216]. The basal tone of the ASM is maintained by the influx and efflux of $\mathrm{Ca}^{2+}$ across the cell membrane, keeping an intracellular basal $\mathrm{Ca}^{2+}$ concentration $\left({ }_{\mathrm{b}}\left[\mathrm{Ca}^{2+}\right]_{\mathrm{i}}\right.$ ) around $100-150 \mathrm{nM}[33,77,217-219]$. The SR, ion channels, GPCRs, ATPases, and other mechanisms preserve ${ }_{b}\left[\mathrm{Ca}^{2+}\right]_{i}$ in the ASM cells. The mechanisms responsible for the $\mathrm{Ca}^{2+}$ influx are carried out by transient receptor potential canonical 3 (TRPC3), L-VDCCs and T-VDCCs, ROCCs, SOCCs, and reverse-mode $\mathrm{Na}^{+} / \mathrm{Ca}^{2+}$ exchanger $\left(\mathrm{NCX}_{\mathrm{REV}}\right)[77,219]$. Endogenous agonists such as acetylcholine, histamine, and leukotrienes act through the GPCRs- $\alpha$ pathway. These receptors activate the $\mathrm{PLC}_{\beta}$ enzyme, which catalyzes the formation of DAG and $\mathrm{IP}_{3}$, favoring SR $\mathrm{Ca}^{2+}$ release through the $\mathrm{IP}_{3}$ receptor [220]. Increased $\mathrm{Ca}^{2+}$ in the cytosol promotes the release of more $\mathrm{Ca}^{2+}\left(\mathrm{Ca}^{2+}\right.$ sparks) through RyRs; this event is known as $\mathrm{Ca}^{2+}$-induced $\mathrm{Ca}^{2+}$ release (CIRC) [221, 222]. Increase in $\left[\mathrm{Ca}^{2+}\right]_{\mathrm{i}}$ is restored by two ATPases: sarcoplasmic reticulum $\mathrm{Ca}^{2+}$-ATPase (SERCA) and plasma membrane $\mathrm{Ca}^{2+}$-ATPase (PMCA) $[223,224]$. Airway smooth muscle relaxation is predominantly mediated by the sympathetic system. Circulating epinephrine is more important in mediating relaxation in human airways than norepinephrine. In the $\mathrm{ASM}, \beta_{2}$-AR is the main adrenoceptor subtype responsible for the bronchodilator effect [156]. Activation of this receptor triggers the formation of cAMP and, consequently, the activation of PKA [156]. PKA-mediated phosphorylation modulates proteins involved in the control of the airway muscle tone by regulating the $\mathrm{Ca}^{2+}$ availability and inactivating myosin light-chain kinase [225]. Furthermore, it is well known that the activation of the $\beta_{2}$-AR favors hyperpolarization and relaxation of the ASM through the opening of different $\mathrm{K}^{+}$channels $[156,226]$. In the ASM, the main $\mathrm{K}^{+}$ channels are the $\mathrm{Ca}^{2+}$-activated $\mathrm{K}^{+}$channels $\left(\mathrm{K}_{\mathrm{Ca}}\right)$ and $\mathrm{K}_{\mathrm{V}}$ $[227,228] . \mathrm{K}_{\mathrm{Ca}}$ are activated by increases in $\left[\mathrm{Ca}^{2+}\right]_{\mathrm{i}}$ and through the cAMP-PKA signaling pathway $[229,230]$. There are three subfamilies of $\mathrm{K}_{\mathrm{Ca}}$, all of them occurring in airways: high conductance $\left(\mathrm{BK}_{\mathrm{Ca}}\right)$, intermediate conductance $\left(\mathrm{IK}_{\mathrm{Ca}}\right)$, and low conductance $\left(\mathrm{SK}_{\mathrm{Ca}}\right)$ [229]. Moreover, $\mathrm{K}_{\mathrm{V}}$ have been characterized as $\mathrm{K}_{\mathrm{V}} 1.2, \mathrm{~K}_{\mathrm{V}} 1.5$, and $\mathrm{K}_{\mathrm{V}} 7.5$ in the ASM $[227,231]$. Several agonists can lead to the bronchodilation of the ASM involving the opening of distinct $\mathrm{K}^{+}$channels. In this regard, it has been shown that the most critical channels in bronchodilation induced by $5-\mathrm{HT}$ and $\mathrm{ATP}$ are $\mathrm{BK}_{\mathrm{Ca}}$ $[226,228]$. Most recently, our research group demonstrated that both $\mathrm{K}_{\mathrm{Ca}}$ and $\mathrm{K}_{\mathrm{V}}$ are implicated in salbutamol-induced relaxation in guinea pig airways [51].

Sex hormones play a role in the development of lung diseases. Androgens have been associated with asthma. During puberty, girls are more vulnerable to present asthma symptoms than boys, until the fifth life decade, when men become more susceptible than women $[232,233]$. It has been reported that the variations in sex hormones during the menstrual cycle, hormone replacement therapy, and pregnancy have an influence in asthma patients [234-236]. Asthma is a chronic and inflammatory disease, characterized by hyperresponsiveness of the airways (AHR). This phenomenon is presented as an increased reactivity of the ASM to different agonists that leads to exaggerated bronchoconstriction. In addition, this disease is conducted by a type 2 immune response through eosinophils, basophils, mast cells, etc. [237]. However, not all asthma patients course with type 2 inflammation; instead, they can display interleukin17- (IL-17-) mediated neutrophil inflammation [238].

Several studies have exposed that $\mathrm{T}$ induces a potential ASM relaxation effect through a nongenomic effect. An early work was conducted in the rabbit tracheal smooth muscle previously contracted with cholinergic agonists. The addition of T relaxed the ASM in an epithelium-dependent way involving NO production [78]. Later on, it was found that $\mathrm{T}$ relaxed precontracted guinea pig and bovine tracheal smooth muscles in an epithelium-independent way by blocking L-VDCCs [76]. In this context, our group demonstrated that T blocked L-VDCCs and SOCCs in the guinea pig ASM [34]. Additionally, the same study revealed that $\mathrm{T}$ induced the synthesis of prostaglandin $\mathrm{E}_{2}\left(\mathrm{PGE}_{2}\right)$, the main relaxing prostanoid in the airways [34]. Our studies pointed out that the blockade of the L-VDCCs and SOCCs and the production of $\mathrm{PGE}_{2}$ are the main components of the T-induced relaxation in guinea pig precontracted airways. Then, we observed that $\mathrm{T}$ did not only relax the guinea pig ASM but lowered ${ }_{\mathrm{b}}\left[\mathrm{Ca}^{2+}\right]_{\mathrm{i}}$ and the muscular tone through the inhibition of L-VDCCs and TRPC3 [77, 219]. Most recently, our research group found that $\mathrm{T}$ interfered with the $\mathrm{IP}_{3}$ receptor, decreasing the cholinergic-induced guinea pig ASM contraction [33]. Noteworthy, all the previously mentioned effects of T on ASM were carried out through nongenomic effects. Likewise, $\mathrm{T}$, via a genomic action, negatively regulates type 2 inflammation and the expression of IL-17A [239, 240]. Furthermore, it was found that androgens, via $A R$ activation, mediate the regulation of intracellular $\mathrm{Ca}^{2+}$ increment induced by proinflammatory cytokines such as tumor necrosis factor alpha (TNF- $\alpha$ ) or interleukin-13 (IL-13) in the human ASM [52]. All these 
androgen effects contribute to diminishing the ASM reactivity and favor the absence of asthma symptoms.

3.1. The Effects of Testosterone on Adrenergic Receptors in the Airway Smooth Muscle. Treatment with $\beta$-agonists to reverse airway obstruction, as seen in asthma and chronic obstructive pulmonary disease (COPD), has an essential role in controlling exacerbations. Therapeutically, there are two types of $\beta$-agonists: long-acting $\beta$-agonists to manage asthma together with glucocorticoids and short-acting $\beta$-agonists to relieve exacerbations [241]. Physiologically, the circulating catecholamines mediate the relaxation of the airways in humans. The androgen effects on the expression or function of the $\beta$-AR in the ASM have been scantly studied. In 1972, Salt and Iverson reported that T, via a nongenomic action, acted as an inhibitor of the extraneuronal uptake for catecholamines in the CM [242]. In this context, it was found that $\mathrm{T}$ potentiated the relaxation induced by isoprenaline (a nonselective $\beta$-adrenergic agonist) in pig bronchus, also via a nongenomic effect. The authors claimed that the potentiation effect observed was due to the inhibition of catechol-O-methyl transferase (COMT) or abolition of extraneuronal uptake [243]. In 2008, Bordallo et al. showed that $5 \alpha$-DHT (a reduced metabolite of T) potentiated the relaxation induced by salbutamol, a $\beta_{2}$-adrenergic agonist, in the bovine tracheal ASM [76]. However, the effect of $5 \alpha$-DHT seemed not to be related to a direct interaction with $\beta_{2}$-AR. Although the authors did not define the cause of the potentiation, it might be related to the inhibition of both the uptake of catecholamines and COMT (Figure 3(a)). Most recently, our group studied the genomic effects of T on $\beta_{2}$-AR. We found that chronic guinea pig ASM exposure to T augmented the expression of $\beta_{2}$-AR and evoked an increase in the relaxing responses to salbutamol (Figure 3(b)). Interestingly, this effect was abolished by flutamide (antagonist of the AR) [51]. We also observed that T potentiated salbutamol-induced potassium currents $\left(\mathrm{I}_{\mathrm{K}}\right)$ involving the $\mathrm{K}_{\mathrm{V}}$ and $\mathrm{K}_{\mathrm{Ca}}$ upregulation (Figure $3(\mathrm{~b})$ ). Contrasting with other studies in the VSM [79], we did not find any modification of the adenylyl cyclase 6 (AC-6, the main isoform in the ASM) expression in tissues chronically exposed to T [51]. In summary, in the ASM, T and its metabolites, through nongenomic and genomic actions, have complementary effects. Consequently, androgens might play an important role as potential physiological modulators of the ASM tone, facilitating relaxation via $\beta_{2}-\mathrm{AR}$, and therefore could be a therapeutic alternative for asthma treatment, although further research is needed (Figure 3).

\section{Cardiac Muscle}

Traditionally in the CM, autonomic control is derived by extrinsic signals or electrical stimulation of peripheral nerves. Moreover, neurocardiac control is maintained by an extensive network of intrinsic cardiac neurons, i.e., the intrinsic cardiac nervous system (ICNS) [244-246]. The ICNS comprises collections of neuronal somas residing on supraventricular tissues and the epicardial surface. This system is also composed by connecting nerve fibers known as ganglionic plexuses (GPs) $[222,246]$. GPs are distributed in 5-7 regions comprising the right dorsal atrial, ventral right atrial, left dorsal, ventral left atrial, middle dorsal, right coronary, and left coronary plexuses [247]. Neuronal activity is modified by the activation of sensory nerves [248] and neuroactive chemicals, including acetylcholine, histamine, $\alpha$ - and $\beta$-adrenergic agonists, NO, neuropeptide Y (NPY, coreleased alongside norepinephrine), and calcitonin generelated peptide (CGRP) [246, 249].

Similar to other muscular cells, $\left[\mathrm{Ca}^{2+}\right]_{\mathrm{i}}$ determines the contractile function of the heart through distinct $\mathrm{Ca}^{2+}$ handling proteins. In the sinoatrial node, the pacemaker cells start depolarization of the cardiac myocytes. This process is regulated by the parasympathetic nervous system (PNS) and the SNS [250]. The self-depolarization produces action potentials along the $\mathrm{CM}$, allowing the influx of $\mathrm{Ca}^{2+}$ through L-VDCCs and T-VDCCs. Furthermore, the $\mathrm{Ca}^{2+}$ influx elicits calcium release from the SR via RyR isoform $2\left(\mathrm{RyR}_{2}\right)$ [251]. Cardiac contraction results from a sudden increase in $\left[\mathrm{Ca}^{2+}\right]_{\mathrm{i}}$ and the formation of the $\mathrm{Ca}^{2+}$-calmodulin complex with the further activation of MLCK. Afterward, $\mathrm{Ca}^{2+}$ is sequestered to the SR by SERCA, and the cell takes it out by the $\mathrm{Na}^{+}-\mathrm{Ca}^{2+}$ exchanger in its forward mode (NCX). In addition, $\mathrm{K}_{\mathrm{Ca}}$ channels are activated, leading to membrane hyperpolarization. These are the main mechanisms responsible for CM relaxation [252, 253]. Physiologically, catecholamines, through $\beta$-ARs, induce the synthesis of cAMP and the activation of PKA. This kinase promotes cardiac contraction by phosphorylating the L-VDCCs and $\mathrm{RyR}_{2}$ since they increase their open probability and therefore the increment in $\left[\mathrm{Ca}^{2+}\right]_{\mathrm{i}}[254,255]$. PKA is also capable of evoking the relaxation of the CM by phosphorylating PLB, allowing SERCA to pump $\mathrm{Ca}^{2+}$ into the SR more rapidly [256]. In human ventricular cardiomyocytes, $\beta_{1}$ - and $\beta_{2}$-ARs enhance cardiac frequency and contractility; meanwhile, $\beta_{3}$ ARs mediate negative inotropic effects [257]. The $\beta_{2}$-ARs essentially trigger the $\mathrm{G}_{s} / \mathrm{AC} / \mathrm{cAMP} / \mathrm{PKA}$ pathway but are also involved in nonclassical $G_{i}$ signaling displaying adverse effects on PKA activation and the inotropic response mediated by $\mathrm{G}_{\mathrm{s}}$ [258].

There is increasing evidence that gender is highly related to cardiovascular states of health and disease. Whether androgens play a significant role in these dissimilarities is still investigated. Moreover, the genomic effects of $\mathrm{T}$ on ventricular cardiomyocytes' performance have been demonstrated. In this regard, Golden et al. showed that this androgen increased the mRNA expression of several critical $\mathrm{Ca}^{2+}$-handling proteins. Treatment of rat ventricular cardiomyocytes with Tincreased the levels of gene expression of L-VDCC, $\beta_{1}$-AR, and NCX with 8 and 24 hours of exposure [259]. The T-induced changes in the mRNA expression levels of the mentioned proteins could be related to the improvement of the function of the cardiomyocytes and also be implicated in the development of hypertrophy and heart failure. These results point out an essential role of $\mathrm{T}$ in sexrelated differences in the cardiac function.

Besides their electrophysiological properties, VDCCs are also classified using a standard nomenclature based on their 


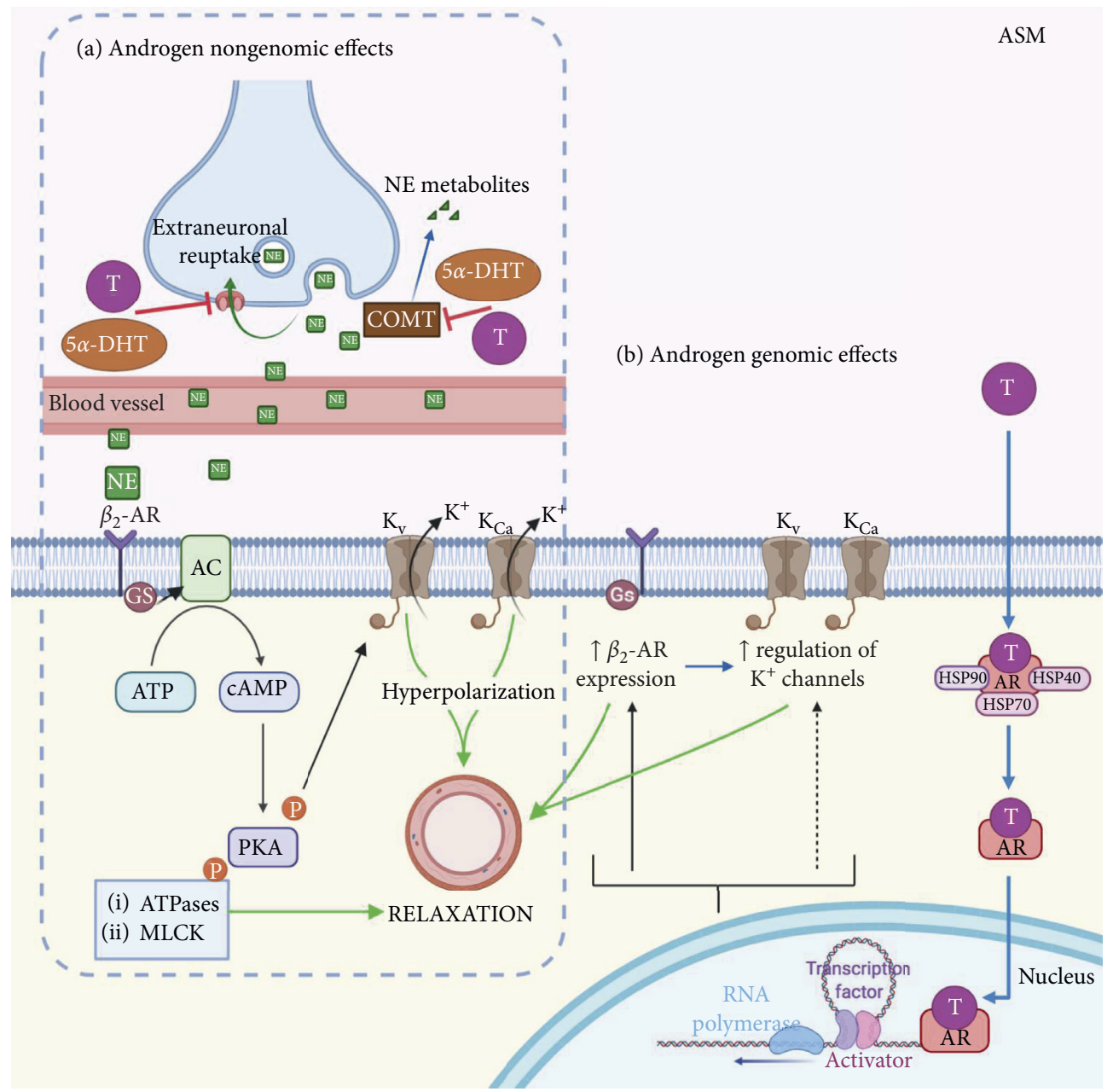

Figure 3: Androgen effects on the adrenergic system in the airway smooth muscle (ASM). (a) Testosterone (T), through a nongenomic effect, potentiates the relaxation induced by the $\beta_{2}$-adrenergic agonist through the inhibition of catechol-O-methyl transferase (COMT) or by the abolition of extraneuronal uptake of catecholamines. The inhibition of these mechanisms by Tor $5 \alpha$-dihydrotestosterone ( $5 \alpha$-DHT, a reduced metabolite of T) leads to the accumulation of catecholamines such as norepinephrine (NE). The $\beta_{2}$-adrenergic agonist activates adenylyl cyclase (AC), leading to the activation of protein kinase A (PKA), which phosphorylates $\mathrm{K}^{+}$channels, ATPases, and myosin lightchain kinase (MLCK). These targets promote the relaxation of the ASM. (b) The androgen receptor (AR) signaling involves androgen crossing the plasma membrane, entering the cytoplasm, dissociation of chaperone proteins, and binding to the AR. Testosterone stimulation increases the $\beta_{2}$-adrenergic receptor $\left(\beta_{2}\right.$-AR) expression in the guinea pig ASM and upregulates the $\mathrm{Ca}^{2+}$-activated $\mathrm{K}^{+}$channels $\left(\mathrm{K}_{\mathrm{Ca}}\right)$ and the voltage-dependent delayed rectifier $\mathrm{K}^{+}$channels $\left(\mathrm{K}_{\mathrm{V}}\right) . \mathrm{K}_{\mathrm{Ca}}$ are activated by increases in intracellular $\mathrm{Ca}^{2+}$ and through the cAMP-PKA signaling pathway. In the ASM, the main $\mathrm{K}^{+}$channels are the $\mathrm{Ca}^{2+}$-activated $\mathrm{K}^{+}$channels of high conductance $\left(\mathrm{BK}_{\mathrm{Ca}}\right)$. The $\mathrm{K}_{\mathrm{V}}$ channel subtypes characterized in the ASM are $\mathrm{K}_{\mathrm{V}} 1.2$ and $\mathrm{K}_{\mathrm{V}} 1.5$. $\mathrm{T}$ (nongenomic and genomic effects) favors the relaxation of the ASM and might contribute to decreasing asthma symptoms.

molecular features of the pore-forming $\alpha 1$-subunit. Therefore, VDCCs are named using the chemical symbol of the permeating ion $(\mathrm{Ca})$ with the physiological modulator (voltage) indicated as a subscript $\left(\mathrm{Ca}_{\mathrm{V}}\right)$. A numerical identifier resembles the channel $\alpha 1$-subunit gene subfamily ( 1 to 3 ) and the order of discovery of the $\alpha 1$-subunit within that subfamily ( 1 through $n$ ). According to this nomenclature, the L-VDCCs are represented by $\mathrm{Ca}_{\mathrm{V}} 1.1-\mathrm{Ca}_{\mathrm{V}} 1.4$ subunits, and T-VDCCs correspond to $\mathrm{Ca}_{\mathrm{V}} 3.1-\mathrm{Ca}_{\mathrm{V}} 3.3$ [260]. In this regard, it has been reported that chronic administration of $\mathrm{T}$ enhanced $\mathrm{Ca}^{2+}$ influx through $\mathrm{L}$ - and T-VDCCs due to an increased expression of the $\mathrm{Ca}_{\mathrm{V}} 1.2$, $\mathrm{Ca}_{\mathrm{V}} 3.1$, and $\mathrm{Ca}_{\mathrm{V}} 3.2$ subunits in ventricular cardiomyocytes, initially upgrading their performance but subsequently bringing the cell into new ${ }_{b}\left[\mathrm{Ca}^{2+}\right]_{\mathrm{i}}[261,262]$. These studies suggest that augmented ${ }_{b}\left[\mathrm{Ca}^{2+}\right]_{\mathrm{i}}$, via the upregulation of the $\mathrm{Ca}^{2+}$ channels aforementioned, might contribute to chronic cardiac pathogenesis when $\mathrm{T}$ levels are elevated.

While the nongenomic effects of T on the CM have been reported, the studies are scarce and seem to be contradictory regarding the $\mathrm{Ca}^{2+}$ handling and the cardiac contraction/ relaxing outcomes. On the one hand, a group of researchers demonstrated in cultured rat cardiomyocytes that the acute exposure to $\mathrm{T}$ rapidly increased $\left[\mathrm{Ca}^{2+}\right]_{\mathrm{i}}$, and this augment was not abolished by an antagonist of the androgen receptor. Elegantly, the authors confirmed that the mechanism involved in the $\mathrm{T}$-induced increase in $\left[\mathrm{Ca}^{2+}\right]_{\mathrm{i}}$ was mediated by the activation of a plasma membrane AR associated with a 
pertussis toxin- (PTX-) sensitive G protein (Gi/o) and with the activation of the PLC-IP ${ }_{3}$ signaling pathway leading to cardiac hypertrophy and failure [263]. The activation of PLC may be mediated through the action of $\beta \gamma$-subunits of the Gi/o proteins $[264,265]$. On the other hand, it has been shown that acute exposure of $\mathrm{T}$ decreased the $\mathrm{L}-$ and T-VDCC activity by reducing their open probability $[262,266]$.

\subsection{The Effects of Testosterone on Adrenergic Receptors in the} Cardiac Muscle. Gender-related differences in cardiovascular disease (CVD) seem to be affected by age. It is well documented that the risk of dying for men between ages 45 and 64 from a CVD is higher than for women in the premenopausal period; however, there is a slight increase in the risk of CVD death in women after menopause [267].

The role of sex hormones in CVD is still unclear; particularly, a controversy about the effects of $\mathrm{T}$ in cardiovascular (CV) health and disease currently exists in the medical community. It is generally accepted that normal levels of $\mathrm{T}$ are beneficial for $\mathrm{CV}$ health in men, and a decline in these levels is related to an increase in CV events [268]. Nevertheless, a potential risk of developing CV events in patients receiving testosterone therapy has been reported $[269,270]$. In postmenopausal women, endogenous elevated levels of total T $(>0.9 \mathrm{nM})$ have been associated with CVD risk factors, such as high blood pressure and insulin resistance [271-275]. In this context, it has been postulated that estrogen augments the levels of sex hormone-binding globulin (SHBG). After menopause, the loss of ovary function leads to a general decline in sex steroid levels. Moreover, the fall of estrogen may lead to decreased levels of SHBG and higher free androgen levels [276]. Therefore, higher androgen levels and decreased estrogen levels in postmenopausal women have been suggested to be partially responsible for the CDV risk [268, 275]. Contrastingly, a study performed by Kaczmarek et al. demonstrated that low $\mathrm{T}$ levels are associated with coronary artery disease (CAD) in postmenopausal females [277]. During the menopausal transition, obesity is closely associated to CVD since it favors the secretion of proinflammatory cytokines, reactive oxygen species (ROS), and prothrombotic mediators [278-282]. Obesity promotes an unfavorable lipid profile which is associated with the development of CVD in elderly women $[283,284]$. This profile is characterized by low high-density lipoprotein (HDL), higher total cholesterol (TC), and triacylglycerol (TAG) plasma levels [285]. In this regard, it was proved that oral DHEA therapy increased HDL and reduced TAG and LDL in adrenal-androgen-deficient postmenopausal women [286]. Also, obesity is a common feature of PCOS, exacerbating its symptoms and conferring a greater risk for CVD. The androgenic status, i.e., hyperandrogenism, needs to be considered when evaluating the metabolic and CV risk in PCOS women [200]. The ongoing controversy regarding the role of $\mathrm{T}$ in CVD might be moderately explained by the interaction between $\mathrm{T}$ and adrenoceptors in cardiac myocytes as discussed in the following.

It has been proposed that low plasmatic levels of $\mathrm{T}$ in older men are associated with an increase in atherosclerosis and cardiovascular risk, suggesting that this androgen plays a cardioprotective role against CVDs, such as coronary heart disease (CHD) and chronic heart failure (CHF) [287]. Moreover, it has been reported that an association between younger age at menopause and a greater risk of $\mathrm{CDH}$ in women coursing a natural menopause process [288]. Furthermore, $\mathrm{T}$ could confer cardiac protection against ischemic injuries by increasing the effects of the $\alpha_{1}$-AR signaling pathway. The activation of $\alpha_{1}$-AR improves the myocardial performance after an infarction, reducing injury and arrhythmias [289]. CHD is characterized by myocardial ischemia and cardiac injury [290]. In this regard, it has been shown that patients with CHD have lower androgen levels than healthy men and that low doses of $\mathrm{T}$ improved ischemic threshold in men suffering from angina [291, 292]. Furthermore, the administration of $\mathrm{T}$ enhanced the function recovery of the myocardium after a no-flow ischemia challenge in rats [293]. These observations point out to a reduction induced by $\mathrm{T}$ in the susceptibility to present myocardial ischemia and favor dilation of the coronary artery [294].

The SNS (through norepinephrine) activates $\alpha$ - and $\beta$-ARs controlling the $\mathrm{CM}$ tone. However, during myocardial ischemia, the release of norepinephrine increases the risk and contributes to cardiac injury [295, 296]. In this regard, it has been shown that the T-induced overexpression of the $\beta_{1}$-AR triggered proapoptotic pathways, weakening the cardiac structure and accelerating heart injury and failure progression $[259,297]$. This overexpression also led to muscle hypertrophy in mice while producing an initial increase in contractility followed by a progressive dysfunction (Figure 4) [298].

On the contrary, the $\alpha_{1}$-ARs may play an important role in cardioprotection, specifically, the $\alpha_{1 \mathrm{~A}}$-subtype. The overexpression of $\alpha_{1 \mathrm{~A}}$-AR can improve the outcome after myocardial infarction [299], cardiac contractility, and reduced arrhythmias $[119,300]$. In 2008, Tsang et al. demonstrated in rat ventricular myocytes that $\mathrm{T}$ replacement therapy (TRT) upregulated the $\alpha_{1}$-AR expression and augmented the cardiac responses, leading to a reduction in ischemia and cardiac injury [289]. Later on, in 2009, the same research group demonstrated that $\mathrm{T}$ enhanced the contractile function induced by the stimulation of both $\alpha_{1^{-}}$ and $\beta_{1}$-AR in perfused rat hearts (Figure 4). Also, T treatment accelerated the relaxing response of the cardiac tissue. Interestingly, both phenomena were mediated by the AR [301]. The enhanced contractile response was explained since $\mathrm{T}$ augmented the function of RyR, leading to increased $\mathrm{Ca}^{2+}$ release from the SR. Otherwise, the augmented relaxing response was due to a more efficient activity of NCX regarding $\alpha_{1}$-AR stimulation and a heightened SERCA activity, accompanied with increased phosphorylation of PLB in the case of $\beta_{1}$-AR stimulation [301]. Interestingly, they additionally found that the absence of T downregulated the expression of $\beta_{2}-\mathrm{AR}$ in rat hearts, indicating that this androgen may also interact with this receptor subtype [289]. Moreover, it has been documented that the activation of $\beta_{2^{-}}$ AR reduced apoptosis and increased the contractile mechanisms but did not accelerate relaxation as $\alpha_{1}$-AR and $\beta_{1}$-AR 


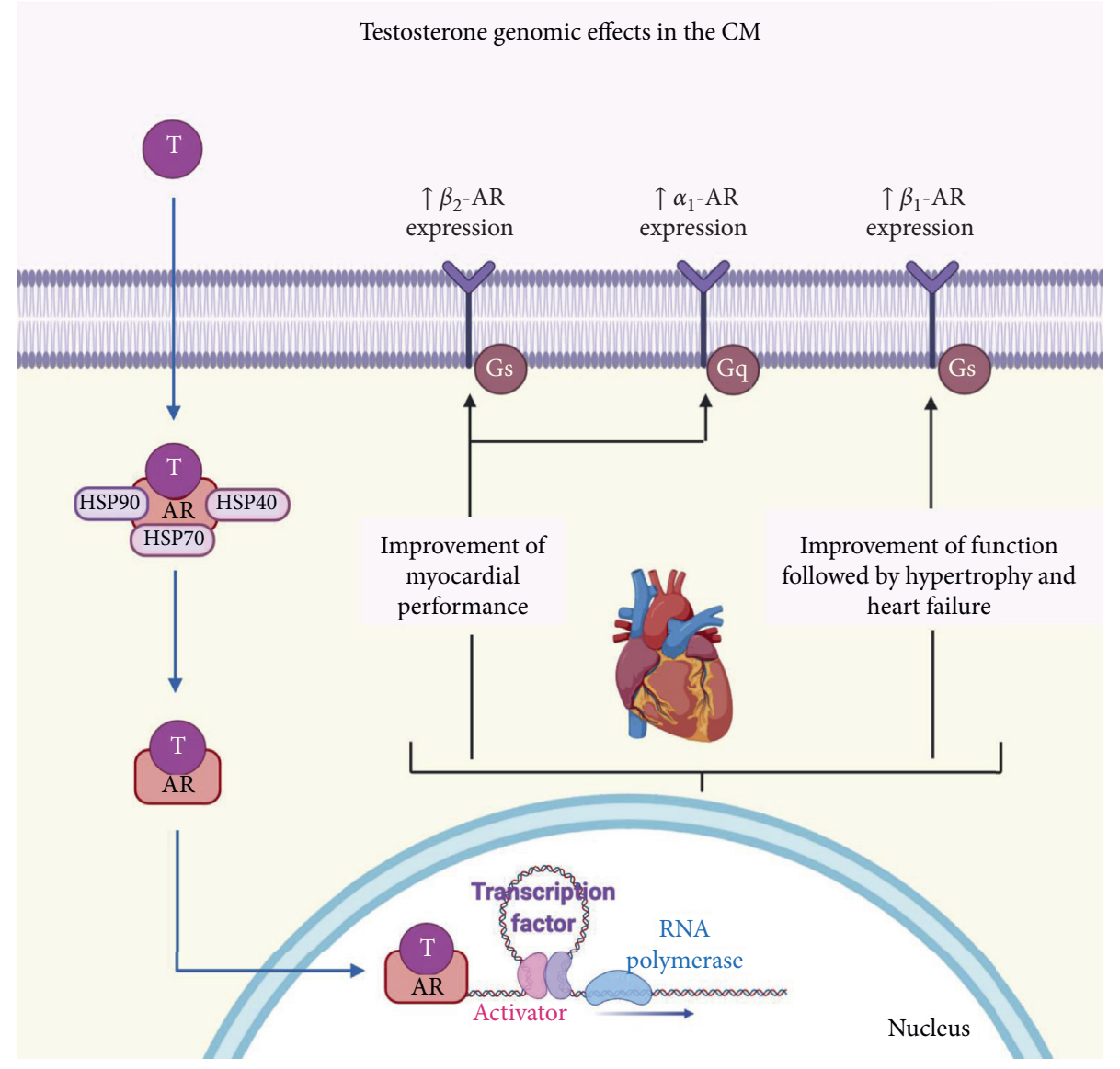

FIGURE 4: Genomic androgen effects on the adrenergic system in the cardiac muscle (CM). The genomic AR signaling involves androgen crossing the plasma membrane, entering the cytoplasm, dissociation of chaperone proteins, and binding to the AR. Testosterone (T) stimulates the expression of the $\alpha_{1}$-adrenergic receptor $\left(\alpha_{1}-\mathrm{AR}\right)$ and $\beta_{2}$-adrenergic receptor $\left(\beta_{2}\right.$-AR), improving ionotropic activity and leading to the development of contraction without cardiotoxic effects. In addition, T increments the expression of the $\beta 1$ adrenergic receptor $(\beta 1-\mathrm{AR})$, acutely improving the cardiomyocytes' function, but chronically leading to hypertrophy and heart failure.

stimulation did [302]. Although several studies have conducted about the relationship between cardiac function and androgens, more information is required to determine if $\mathrm{T}$ might play a key role in CHD.

Testosterone has also been associated with CHF [303]. This disease is a metabolic syndrome characterized by endocrine and inflammatory alterations, including elevated circulating catecholamine levels [304]. Testosterone deficiency (in hypogonadal subjects) has been demonstrated in $26 \%$ to $37 \%$ of male patients with $\mathrm{CHF}[305,306]$. Moreover, drugs used in CHF treatment, e.g., spironolactone and $\beta$-blockers, may diminish the function of Leydig cells, leading to a decline in the production of $\mathrm{T}[307,308]$. The low levels of $\mathrm{T}$ have been associated with reduced ejection fraction and increased systemic vascular resistance [309]. In this regard, the effects of T on $\beta$-AR have been investigated. In 2011, Sun et al. demonstrated that a TRT in a heart failure rat model reversed the damage (decrease in contractility, apoptosis, and fibrosis in cardiomyocytes) through the protection of the cardiac $\beta$-adrenergic system. Notably, the stimulation of the AR by T upregulated the expression of $\beta_{2^{-}}$ AR, improving the myocardial performance (Figure 4) [163]. Furthermore, it has been proposed that TRT in men with
CHF induced an increase in the cardiac output and afterload [310].

The genomic regulation of the $\beta$-AR has been associated with cardiac remodeling and heart failure $[311,312]$. In this regard, it has been shown that exercise training in rats reverses $\beta$-AR dysfunction by reducing the levels of $G$ proteincoupled receptor kinase-2 (GRK2), an enzyme implicated in $\beta_{1}$-AR and $\beta_{2}$-AR dysregulation in CHF [313-315]. Moreover, exercise seems to restore the adrenal GRK2/ $\alpha_{2}-\mathrm{AR} /$ catecholamine production axis [313]. Also, exercise augments vascular $\beta$-AR responsiveness and diminishes the activity of GRK2 [316]. Interestingly, $\beta_{1}$-AR expression in the heart would be directly influenced by anabolic-androgenic steroids (AAS, synthetic derivatives of T) [317]. The use of AAS in combination with resistance training frequently improves the physical performance and helps athletes gain muscle mass and strength $[318,319]$. However, numerous AAS abuse side effects include endocrine (hypogonadism) and detrimental cardiovascular issues [320-322]. For instance, vigorous training, anabolic steroid abuse, and the sympathetic nervous system's stimulation in mice increased cardiac levels of IL- $1 \beta$ and TNF- $\alpha$ and plasmatic levels of total cholesterol [320]. Furthermore, it 
has been demonstrated that the use of AAS induced cardiac hypertrophy and increased myocardial susceptibility to ischemia injury [322, 323]. In this context, the administration of nandrolone (AAS) to male rats under an exercise training protocol increased the expression of $\beta_{1^{-}}$and $\beta_{2}$-AR in the cardiac right atrium, provoked the prolongation of the QTc interval, and increased the BP [324]. In addition, the exposure of nandrolone augmented hypertension in SHR rats and $\beta_{1}$-AR protein expression in the left ventricle [317]. These data suggest that myocardial injury may be predisposed by high-performance training, steroid abuse, and the sympathetic nervous system's stimulation. Moreover, these insights may explain cardiac ailments and deaths in athletes under an AAS regimen.

Given the differences between studies showing the protective role of $\mathrm{T}$ in $\mathrm{CV}$ events and reports pointing out adverse CVD outcomes, it has been remarkably proposed that the use of $\mathbf{T}$, as a treatment in CVD, should only be considered for male patients with a diagnosis of hypogonadism. Moreover, due to the increase of $\mathrm{T}$ therapy for postmenopausal women, the potential risk of developing CDV events needs further research $[268,275]$.

\section{Conclusions}

The adrenergic system plays a pivotal role in the control of vascular, airway, and cardiac physiology. A relationship between androgens with the adrenergic system of these tissues is proposed. This review summarizes that, in the vascular smooth muscle, $\mathrm{T}$, via the androgen receptor, reduces the AC expression and increases the $\alpha_{1}$-AR expression, leading to high BP and hypertension. Moreover, in the airway smooth muscle, $\mathrm{T}$, via nongenomic action, potentiates the $\beta$-adrenergic-induced relaxation through the inhibition of COMT or by the abolition of extraneuronal uptake. This androgen, via a genomic effect, also augments the expression of $\beta_{2}$-AR and induces an increase in the relaxing responses to salbutamol. In the cardiac muscle, $\mathrm{T}$ upregulates the expression of $\alpha_{1 \mathrm{~A}}-\mathrm{AR}$ and $\beta_{2}$-AR mediated by the AR signaling, improving the myocardial performance. Moreover, $\mathrm{T}$ also increments $\beta 1$-AR expression, improving the cardiomyocytes' function; however, the enhancement in muscle work during a long period ends up developing hypertrophy and heart failure.

Consequently, we might argue that androgen genomic actions have deleterious effects in the VSM favoring hypertension. Nevertheless, in the ASM, nongenomic and genomic actions of androgens contribute to diminish the hyperresponsiveness of this tissue, favoring the absence of asthma symptoms. Therefore, androgens could be a therapeutic alternative for asthma treatment. However, in heart diseases, further research is required to determine the possible therapeutic use of androgens in these ailments.

Finally, the use of T and DHEA as a therapeutic tool for the treatment of asthma symptoms or some cardiovascular diseases, is questionable. $\mathrm{T}$ has virilizing adverse effects, androgenic actions that favor prostate cancer, and its aromatization leads to the production of estrogens. Additionally, DHEA is further biotransformed into various sex steroids, such as $\mathrm{T}$ and estrogens, with their subsequent effects. However, 5 $\beta$-DHT, a well-known $\mathrm{T}$ metabolite without genomic effects, could be a prospective therapeutic agent for the treatment of these illnesses.

\section{Abbreviations}

AAS: Anabolic-androgenic steroids

AC: Adenylyl cyclase

AC-6: Adenylyl cyclase 6

AHR: Airway hyperresponsiveness

$\alpha_{1}$-ARs: $\quad$ Alpha-1-adrenergic receptors

$\alpha_{2}$-ARs: Alpha-2-adrenergic receptors

ANF: Atrial natriuretic factor

AR: $\quad$ Androgen receptor

ASM: $\quad$ Airway smooth muscle

Basic Fibroblast growth factor

bFGF:

$\beta$-ARs: $\quad$ Beta-adrenergic receptors

$\mathrm{BK}_{\mathrm{Ca}}$ : $\quad \mathrm{Ca}^{2+}$-activated $\mathrm{K}^{+}$channels of high conductance

BP: $\quad$ Blood pressure

cAMP: $\quad 3^{\prime}, 5^{\prime}$-Cyclic adenosine monophosphate

cGMP: $\quad 3^{\prime}, 5^{\prime}$-Cyclic guanosine monophosphate

CGRP: Calcitonin gene-related peptide

CHD: Coronary heart disease

CHF: $\quad$ Chronic heart failure

CIRC: $\quad \mathrm{Ca}^{2+}$-induced $\mathrm{Ca}^{2+}$ release

CM: $\quad$ Cardiac muscle

COMT: Catechol-O-methyl transferase

COPD: Chronic obstructive pulmonary disease

CV: Cardiovascular

CVD: Cardiovascular disease

DAG: Diacylglycerol

DHEA: Dehydroepiandrosterone

$5 \alpha$-DHT: $5 \alpha$-Dihydrotestosterone

5 $\beta$-DHT: $5 \beta$-Dihydrotestosterone

EGFR: Epidermal growth factor receptor

ERK1/2: Extracellular signal-regulated kinases 1 and 2

FSH: Follicle-stimulating hormone

GDP: Guanosine diphosphate

GPRC6A: G protein-coupled receptor family $\mathrm{C}$ group 6member A

GPCR ${ }_{\mathrm{q}} \alpha$ : GPCRs coupled to the ${ }_{\mathrm{q}} \alpha$ subunit

GPCRs: $\quad G$ protein-coupled receptors

GPCR ${ }_{s} \alpha$ : GPCRs coupled to the ${ }_{s} \alpha$ subunit

GRK2: $\quad$ G protein-coupled receptor kinase-2

GPs: $\quad$ Ganglionic plexuses

GTP: Guanosine-5' -triphosphate

HA: Hyperandrogenism

HDL: High-density lipoprotein

HGFR: Hepatocyte growth factor receptor

$3 \beta$-HSD: $3 \beta$-Hydroxysteroid dehydrogenase

17 $\beta$-HSD: $17 \beta$-Hydroxysteroid dehydrogenase

ICNS: Intrinsic cardiac nervous system

$\mathrm{I}_{\mathrm{K}}$ : $\quad \mathrm{K}^{+}$currents

$\mathrm{IK}_{\mathrm{Ca}}$ : $\quad \mathrm{Ca}^{2+}$-activated $\mathrm{K}^{+}$channels of intermediate conductance

IL-13: Interleukin-13

IL-17: $\quad$ Interleukin 17 
$\mathrm{IP}_{3}$

Inositol-1, 4, 5-triphosphate

${ }_{b}\left[\mathrm{Ca}^{2+}\right]_{\mathrm{i}}$ : Intracellular basal $\mathrm{Ca}^{2+}$ concentration

$\left[\mathrm{Ca}^{2+}\right]_{\mathrm{i}}$ : Intracellular $\mathrm{Ca}^{2+}$ concentration

$\mathrm{K}_{\mathrm{ATP}}$ : $\quad$ ATP-sensitive $\mathrm{K}^{+}$channels;

$\mathrm{K}_{\mathrm{Ca}}: \quad \mathrm{Ca}^{2+}$-activated $\mathrm{K}^{+}$channels

$\mathrm{K}_{\mathrm{IR}}: \quad$ Inward-rectifier $\mathrm{K}^{+}$channels

$\mathrm{K}_{\mathrm{V}}$ : $\quad$ Voltage-dependent delayed rectifier $\mathrm{K}^{+}$channels

$\mathrm{K}_{\mathrm{V}}$ 1.5: $\quad$ Voltage-dependent delayed rectifier $\mathrm{K}^{+}$channel 1.5

LH: $\quad$ Luteinizing hormone

L- $\quad$ L-type voltage-dependent $\mathrm{Ca}^{2+}$ channels

VDCCs:

MAPKs: Mitogen-activated protein kinases

MEK: $\quad$ Mitogen-activated protein kinase kinase

MLCK: Myosin light-chain kinase

NCX: $\quad \mathrm{Na}^{+}-\mathrm{Ca}^{2+}$ exchanger

NCX ${ }_{\text {REV }}:$ Reverse-mode $\mathrm{Na}^{+} / \mathrm{Ca}^{2+}$ exchanger

NO: $\quad$ Nitric oxide

NPY: $\quad$ Neuropeptide Y

PCa: $\quad$ Prostate cancer

PCOS: Polycystic ovary syndrome

PDGF: Platelet-derived growth factor

$\mathrm{PGE}_{2}$ : $\quad$ Prostaglandin $\mathrm{E}_{2}$

PI3K: $\quad$ Phosphatidylinositol 3-kinase

PKA: $\quad$ Protein kinase A

PKC: $\quad$ Protein kinase $\mathrm{C}$

PKG: $\quad$ Protein kinase $G$

PLB: $\quad$ Phospholamban

PLC: $\quad$ Phospholipase C

PLC $_{\beta}: \quad$ Phospholipase $\mathrm{C}_{\beta}$

PMCA: Plasma membrane $\mathrm{Ca}^{2+}$-ATPase

PNS: $\quad$ Parasympathetic nervous system

PTX: $\quad$ Pertussis toxin

ROCCs: Receptor-operated $\mathrm{Ca}^{2+}$ channels

$\mathrm{RyR}_{2}$ : $\quad$ RyR isoform 2

RyRs: $\quad$ Ryanodine receptors

SERCA: Sarcoplasmic reticulum $\mathrm{Ca}^{2+}$-ATPase

5-HT: Serotonin

SHR: Spontaneously hypertensive rats

$\mathrm{SK}_{\mathrm{Ca}}$ : $\quad \mathrm{Ca}^{2+}$-activated $\mathrm{K}^{+}$channels of low conductance

SNS: $\quad$ Sympathetic nervous system

SOCCs: Store-operated $\mathrm{Ca}^{2+}$ channels

SR: $\quad$ Sarcoplasmic reticulum

T: $\quad$ Testosterone

TAG: Triacylglycerol

TC: $\quad$ Total cholesterol

TNF- $\alpha$ : $\quad$ Tumor necrosis factor alpha

TRPC: Transient receptor potential channels

TRPC3: $\quad$ Transient receptor potential canonical 3

TRT: $\quad$ Testosterone replacement therapy

$\mathrm{T}$ - $\quad$ T-type voltage-dependent $\mathrm{Ca}^{2+}$ channels

VDCCs:

VDCCs: Voltage-dependent $\mathrm{Ca}^{2+}$ channels

VEGFR- Vascular endothelial receptors $1 / 2$

$1 / 2$ :

VSM: Vascular smooth muscle

ZIP9: $\quad$ Zinc-regulated transporter [Zrt]-protein 9.

\section{Data Availability}

No data were used to support this study.

\section{Disclosure}

Figures of this review were created with BioRender.com.

\section{Conflicts of Interest}

The authors declare that they have no conflicts of interest.

\section{Authors' Contributions}

Abril Carbajal-García and Jorge Reyes-García contributed equally to this work.

\section{Acknowledgments}

Abril Carbajal-García is grateful to the Programa de Doctorado en Ciencias Biomédicas, Universidad Nacional Autónoma de México, for the instruction received during her studies to get a $\mathrm{PhD}$ degree. She received fellowship from the Consejo Nacional de Ciencia y Tecnología, México (application \# 2018-000068-02NACF-17950; CVU 826027). Jorge Reyes-García is grateful to Posgrado en Ciencias Biológicas, UNAM, and Consejo Nacional de Ciencia y Tecnología for the support to obtain a Postdoctoral fellowship (EPE-2019, CONACYT). This study was partly supported by grants from Dirección General de Asuntos del Personal Académico (DGAPA), Universidad Nacional Autónoma de México (IN204319) and CONACYT (137725) to LM Montaño.

\section{References}

[1] F. Bidlingmaier, H. G. Dörr, W. Eisenmenger, U. Kuhnle, and D. Knorr, "Contribution of the adrenal gland to the production of androstenedione and testosterone during the first two years of life," The Journal of Clinical Endocrinology \& Metabolism, vol. 62, no. 2, pp. 331-335, 1986.

[2] A. K. Lucas-Herald, R. Alves-Lopes, A. C. Montezano, S. F. Ahmed, and R. M. Touyz, "Genomic and non-genomic effects of androgens in the cardiovascular system: clinical implications," Clinical Science, vol. 131, no. 13, pp. 1405-1418, 2017.

[3] V. Luu-The and F. Labrie, "The intracrine sex steroid biosynthesis pathways," Progress in Brain Research, vol. 181, pp. 177-192, 2010.

[4] Y. Wang, H. Li, Q. Zhu, X. Li, Z. Lin, and R.-S. Ge, "The cross talk of adrenal and Leydig cell steroids in Leydig cells," The Journal of Steroid Biochemistry and Molecular Biology, vol. 192, Article ID 105386, 2019.

[5] W. L. Miller and R. J. Auchus, "The molecular biology, biochemistry, and physiology of human steroidogenesis and its disorders," Endocrine Reviews, vol. 32, no. 1, pp. 81-151, 2011.

[6] L. L. Martin, C. Kubeil, A. N. Simonov et al., "Electrochemistry of cytochrome P450 17 $\alpha$-hydroxylase/17, 20-lyase (P450c17)," Molecular and Cellular Endocrinology, vol. 441, pp. 62-67, 2017. 
[7] J. P. Preslocsk, "Steroidogenesis in the mammalian testis," Endocrine Reviews, vol. 1, no. 2, pp. 132-139, 1980.

[8] L. Di Costanzo, J. E. Drury, D. W. Christianson, and T. M. Penning, "Structure and catalytic mechanism of human steroid 5 $\beta$-reductase (AKR1D1)," Molecular and Cellular Endocrinology, vol. 301, no. 1-2, pp. 191-198, 2009.

[9] D. W. Russell and J. D. Wilson, "Steroid 5a-reductase: two genes/two enzymes," Annual Review of Biochemistry, vol. 63, no. 1, pp. 25-61, 1994.

[10] R. S. Swerdloff, R. E. Dudley, S. T. Page, C. Wang, and W. A. Salameh, "Dihydrotestosterone: biochemistry, physiology, and clinical implications of elevated blood levels," Endocrine Reviews, vol. 38, no. 3, pp. 220-254, 2017.

[11] H. G. Burger, "Androgen production in women," Fertil Steril, vol. 77, no. 4, pp. S3-S5, 2002.

[12] Y. Tian, W. Shen, Z. Lai et al., "Isolation and identification of ovarian theca-interstitial cells and granulose cells of immature female mice," Cell Biology International, vol. 39, no. 5, pp. 584-590, 2015.

[13] L. Schiffer, W. Arlt, and K.-H. Storbeck, "Intracrine androgen biosynthesis, metabolism and action revisited," Molecular and Cellular Endocrinology, vol. 465, pp. 4-26, 2018.

[14] K. M. Kayes-Wandover and P. C. White, "Steroidogenic enzyme gene expression in the human heart," Journal of Clinical Endocrinology \& Metabolism, vol. 85, no. 7, pp. 2519-2525, 2000.

[15] M. J. Young, C. D. Clyne, T. J. Cole, and J. W. Funder, "Cardiac steroidogenesis in the normal and failing heart," The Journal of Clinical Endocrinology \& Metabolism, vol. 86, no. 11, pp. 5121-5126, 2001.

[16] Y. Nakamura, T. Suzuki, T. Inoue et al., " $3 \beta$-hydroxysteroid dehydrogenase in human aorta," Endocrine Journal, vol. 52, no. 1, pp. 111-115, 2005.

[17] S.-F. Du, Q. Yu, K. Chuan et al., "In obese mice, exercise training increases $11 \beta$-HSD1 expression, contributing to glucocorticoid activation and suppression of pulmonary inflammation," Journal of Applied Physiology, vol. 123, no. 4, pp. 717-727, 2017.

[18] P. R. Provost, C. H. Blomquist, C. Godin et al., "Androgen formation and metabolism in the pulmonary epithelial cell line A549: expression of $17 \beta$-hydroxysteroid dehydrogenase type 5 and $3 \alpha$-hydroxysteroid dehydrogenase type 3 ," Endocrinology, vol. 141, no. 8, pp. 2786-2794, 2000.

[19] P. R. Provost, M. Simard, and Y. Tremblay, "A link between lung androgen metabolism and the emergence of mature epithelial type II cells," American Journal of Respiratory and Critical Care Medicine, vol. 170, no. 3, pp. 296-305, 2004.

[20] T. Thum and J. Borlak, "Testosterone, cytochrome P450, and cardiac hypertrophy," The FASEB Journal, vol. 16, no. 12, pp. 1537-1549, 2002.

[21] W. M. Geissler, D. L. Davis, L. Wu et al., "Male pseudohermaphroditism caused by mutations of testicular $17 \beta$ hydroxysteroid dehydrogenase 3," Nature Genetics, vol. 7, no. 1, pp. 34-39, 1994.

[22] N. Harada, H. Sasano, H. Murakami, T. Ohkuma, H. Nagura, and Y. Takagi, "Localized expression of aromatase in human vascular tissues," Circulation Research, vol. 84, no. 11, pp. 1285-1291, 1999.

[23] L. Nathan, W. Shi, H. Dinh et al., "Testosterone inhibits early atherogenesis by conversion to estradiol: critical role of aromatase," Proceedings of the National Academy of Sciences, vol. 98, no. 6, pp. 3589-3593, 2001.
[24] O. K. Weinberg, D. C. Marquez-Garban, M. C. Fishbein et al., "Aromatase inhibitors in human lung cancer therapy," Cancer Research, vol. 65, no. 24, pp. 11287-11291, 2005.

[25] T. W. Kelsey, L. Q. Li, R. T. Mitchell et al., "A validated agerelated normative model for male total testosterone shows increasing variance but no decline after age 40 years," PLoS One, vol. 9, no. 1, Article ID e109346, 2014.

[26] G. Sartorius, S. Spasevska, A. Idan et al., "Serum testosterone, dihydrotestosterone and estradiol concentrations in older men self-reporting very good health: the healthy man study," Clinical Endocrinology, vol. 77, no. 5, pp. 755-763, 2012.

[27] E. A. Townsend, V. M. Miller, and Y. S. Prakash, "Sex differences and sex steroids in lung health and disease," Endocrine Reviews, vol. 33, no. 1, pp. 1-47, 2012.

[28] N. Bruchovsky and J. D. Wilson, "Discovery of the role of dihydrotestosterone in androgen action," Steroids, vol. 64, no. 11, pp. 753-759, 1999.

[29] G. E. Abraham, "Ovarian and adrenal contribution to peripheral androgens during the menstrual cycle," The Journal of Clinical Endocrinology \& Metabolism, vol. 39, no. 2, pp. 340-346, 1974.

[30] M. Lorigo, M. Mariana, M. C. Lemos, and E. Cairrao, "Vascular mechanisms of testosterone: the non-genomic point of view," The Journal of Steroid Biochemistry and Molecular Biology, vol. 196, Article ID 105496, 2020.

[31] M. Pi, K. Kapoor, Y. Wu et al., "Structural and functional evidence for testosterone activation of GPRC6A in peripheral tissues," Molecular Endocrinology, vol. 29, no. 12, pp. 1759-1773, 2015

[32] L. M. Montaño, J. Espinoza, E. Flores-Soto, J. Chávez, and M. Perusquía, "Androgens are bronchoactive drugs that act by relaxing airway smooth muscle and preventing bronchospasm," Journal of Endocrinology, vol. 222, no. 1, pp. 1-13, 2014.

[33] L. M. Montaño, E. Flores-Soto, J. Reyes-García et al., "Testosterone induces hyporesponsiveness by interfering with $\mathrm{IP}_{3}$ receptors in guinea pig airway smooth muscle," Molecular and Cellular Endocrinology, vol. 473, pp. 17-30, 2018.

[34] M. Perusquía, E. Flores-Soto, B. Sommer et al., "Testosterone-induced relaxation involves L-type and store-operated $\mathrm{Ca}^{2+}$ channels blockade, and $\mathrm{PGE}_{2}$ in guinea pig airway smooth muscle," Pflügers Archive-European Journal of Physiology, vol. 467, no. 4, pp. 767-777, 2015.

[35] J. L. Scragg, M. L. Dallas, and C. Peers, "Molecular requirements for L-type $\mathrm{Ca}^{2+}$ channel blockade by testosterone," Cell Calcium, vol. 42, no. 1, pp. 11-15, 2007.

[36] P. Thomas, A. Converse, and H. A. Berg, "ZIP9, a novel membrane androgen receptor and zinc transporter protein," General and Comparative Endocrinology, vol. 257, pp. 130136, 2018.

[37] P. Thomas, Y. Pang, J. Dong, and A. H. Berg, "Identification and characterization of membrane androgen receptors in the ZIP9 zinc transporter subfamily: II. Role of human ZIP9 in testosterone-induced prostate and breast cancer cell apoptosis," Endocrinology, vol. 155, no. 11, pp. 4250-4265, 2014.

[38] C. Wang, Y. Liu, and J.-M. Cao, "G protein-coupled receptors: extranuclear mediators for the non-genomic actions of steroids," International Journal of Molecular Sciences, vol. 15, no. 9, pp. 15412-15425, 2014.

[39] M. Pi, P. Faber, G. Ekema et al., "Identification of a novel extracellular cation-sensing G-protein-coupled receptor," Journal of Biological Chemistry, vol. 280, no. 48, pp. 4020140209, 2005. 
[40] M. Pi, K. Kapoor, R. Ye et al., "Evidence for osteocalcin binding and activation of GPRC6A in $\beta$-cells," Endocrinology, vol. 157, no. 5, pp. 1866-1880, 2016.

[41] M. Pi, Y. Wu, N. I. Lenchik, I. Gerling, and L. D. Quarles, "GPRC6A mediates the effects of ${ }_{L}$-arginine on insulin secretion in mouse pancreatic islets," Endocrinology, vol. 153, no. 10, pp. 4608-4615, 2012.

[42] M. Pi, A. L. Parrill, and L. D. Quarles, "GPRC6A mediates the non-genomic effects of steroids," Journal of Biological Chemistry, vol. 285, no. 51, pp. 39953-39964, 2010.

[43] R. Ye, M. Pi, M. M. Nooh, S. W. Bahout, and L. D. Quarles, "Human GPRC6A mediates testosterone-induced mitogenactivated protein kinases and $\mathrm{mTORC} 1$ signaling in prostate cancer cells," Molecular Pharmacology, vol. 95, no. 5, pp. 563-572, 2019.

[44] A. H. Berg, C. D. Rice, M. S. Rahman, J. Dong, and P. Thomas, "Identification and characterization of membrane androgen receptors in the ZIP9 zinc transporter subfamily: I. Discovery in female atlantic croaker and evidence ZIP9 mediates testosterone-induced apoptosis of ovarian follicle cells," Endocrinology, vol. 155, no. 11, pp. 4237-4249, 2014.

[45] A. Bulldan, R. Dietze, M. Shihan, and G. Scheiner-Bobis, "Non-classical testosterone signaling mediated through ZIP9 stimulates claudin expression and tight junction formation in Sertoli cells," Cellular Signalling, vol. 28, no. 8, pp. 1075-1085, 2016.

[46] A. J. Whitmarsh, "Regulation of gene transcription by mitogen-activated protein kinase signaling pathways," Biochimica et Biophysica Acta (BBA)-Molecular Cell Research, vol. 1773, no. 8, pp. 1285-1298, 2007.

[47] C. A. Heinlein and C. Chang, "The roles of androgen receptors and androgen-binding proteins in nongenomic androgen actions," Molecular Endocrinology, vol. 16, no. 10, pp. 2181-2187, 2002.

[48] C. A. Heinlein and C. Chang, "Androgen receptor (AR) coregulators: an overview," Endocrine Reviews, vol. 23, no. 2, pp. 175-200, 2002.

[49] H. V. Heemers and D. J. Tindall, "Androgen receptor (AR) coregulators: a diversity of functions converging on and regulating the AR transcriptional complex," Endocrine Reviews, vol. 28, no. 7, pp. 778-808, 2007.

[50] H. Fang, W. Tong, W. S. Branham et al., "Study of 202 natural, synthetic, and environmental chemicals for binding to the androgen receptor," Chemical Research in Toxicology, vol. 16, no. 10, pp. 1338-1358, 2003.

[51] A. Carbajal-García, J. Reyes-García, M. F. Casas-Hernández et al., "Testosterone augments $\beta_{2}$ adrenergic receptor genomic transcription increasing salbutamol relaxation in airway smooth muscle," Molecular and Cellular Endocrinology, vol. 510, Article ID 110801, 2020.

[52] R. S. R. Kalidhindi, R. Katragadda, K. L. Beauchamp, C. M. Pabelick, Y. S. Prakash, and V. Sathish, "Androgen receptor-mediated regulation of intracellular calcium in human airway smooth muscle cells," Cellular Physiology and Biochemistry: International Journal of Experimental Cellular Physiology, Biochemistry, and Pharmacology, vol. 53, no. 1, pp. 215-228, 2019.

[53] R. Ma, S. Wu, and Q. Lin, "Homologous up-regulation of androgen receptor expression by androgen in vascular smooth muscle cells," Hormone Research in Paediatrics, vol. 63, no. 1, pp. 6-14, 2005.

[54] J. D. Marsh, M. H. Lehmann, R. H. Ritchie, J. K. Gwathmey, G. E. Green, and R. J. Schiebinger, "Androgen receptors mediate hypertrophy in cardiac myocytes," Circulation, vol. 98, no. 3, pp. 256-261, 1998.

[55] E. Pal, L. Hadjadj, Z. Fontányi et al., "Gender, hyperandrogenism and vitamin $\mathrm{D}$ deficiency related functional and morphological alterations of rat cerebral arteries," PLoS One, vol. 14, Article ID e0216951, 2019.

[56] A. Zarazua, A. González-Arenas, G. Ramírez-Vélez, B. Bazán-Perkins, C. Guerra-Araiza, and M. G. CamposLara, "Sexual dimorphism in the regulation of estrogen, progesterone, and androgen receptors by sex steroids in the rat airway smooth muscle cells," International Journal of Endocrinology, vol. 2016, Article ID 8423192, 11 pages, 2016.

[57] P. Di Giosia, P. Giorgini, C. Andrea Stamerra, M. Petrarca, C. Ferri, and A. Sahebkar, "Gender differences in epidemiology, pathophysiology, and treatment of hypertension," Current Atherosclerosis Reports, vol. 20, no. 3, 2018.

[58] C. Moretti, G. Lanzolla, M. Moretti, L. Gnessi, and E. Carmina, "Androgens and hypertension in men and women: a unifying view," Current Hypertension Reports, vol. 19 , no. 5 , p. $44,2017$.

[59] S. M. Dehm and D. J. Tindall, "Alternatively spliced androgen receptor variants," Endocrine-Related Cancer, vol. 18, no. 5, pp. R183-R196, 2011.

[60] D. G. Hu, T. E. Hickey, C. Irvine et al., "Identification of androgen receptor splice variant transcripts in breast cancer cell lines and human tissues," Hormones and Cancer, vol. 5, no. 2, pp. 61-71, 2014.

[61] S. S. Laurentino, P. I. S. Pinto, J. Tomás et al., "Identification of androgen receptor variants in testis from humans and other vertebrates," Andrologia, vol. 45, no. 3, pp. 187-194, 2013.

[62] C. Lu and J. Luo, "Decoding the androgen receptor splice variants," Translational Andrology and Urology, vol. 2, no. 3, pp. 178-186, 2013.

[63] I. Ahrens-Fath, O. Politz, C. Geserick, and B. Haendler, "Androgen receptor function is modulated by the tissuespecific AR45 variant," FEBS Journal, vol. 272, no. 1, pp. 74-84, 2005.

[64] O. Sartor and Y. Dong, "Androgen receptor variant-7: an important predictive biomarker in castrate resistant prostate cancer," Asian Journal of Andrology, vol. 17, pp. 439-440, 2015.

[65] K. M. Wadosky and S. Koochekpour, "Androgen receptor splice variants and prostate cancer: from bench to bedside," Oncotarget, vol. 8, no. 11, pp. 18550-18576, 2017.

[66] Z. Guo, X. Yang, F. Sun et al., "A novel androgen receptor splice variant is up-regulated during prostate cancer progression and promotes androgen depletion-resistant growth," Cancer Research, vol. 69, no. 6, pp. 2305-2313, 2009.

[67] R. Hu, T. A. Dunn, S. Wei et al., "Ligand-independent androgen receptor variants derived from splicing of cryptic exons signify hormone-refractory prostate cancer," Cancer Research, vol. 69, no. 1, pp. 16-22, 2009.

[68] N. Sperelakis, L. Ramasamy, and B. Kalloor, "Propagated repolarization of simulated action potentials in cardiac muscle and smooth muscle," Theoretical Biology and Medical Modelling, vol. 2, no. 1, p. 5, 2005.

[69] L. Isidoro, M. Ferrer, and M. Perusquía, "Vasoactive androgens: vasorelaxing effects and their potential regulation of blood pressure," Endocrine Research, vol. 43, no. 3, pp. 166-175, 2018.

[70] L. M. Montaño, E. Calixto, A. Figueroa, E. Flores-Soto, V. Carbajal, and M. Perusquía, "Relaxation of androgens on 
rat thoracic aorta: testosterone concentration dependent agonist/antagonist L-type $\mathrm{Ca}^{2+}$ channel activity, and $5 \beta$ dihydrotestosterone restricted to L-type $\mathrm{Ca}^{2+}$ channel blockade," Endocrinology, vol. 149, pp. 2517-2526, 2008.

[71] J. Navarro-Dorado, L. M. Orensanz, P. Recio et al., "Mechanisms involved in testosterone-induced vasodilatation in pig prostatic small arteries," Life Sciences, vol. 83, no. 15-16, pp. 569-573, 2008.

[72] M. Perusquía, E. Navarrete, L. González, and C. M. Villalón, "The modulatory role of androgens and progestins in the induction of vasorelaxation in human umbilical artery," Life Sciences, vol. 81, no. 12, pp. 993-1002, 2007.

[73] P. A. Saldanha, E. Cairrão, C. J. Maia, and I. Verde, "Longand short-term effects of androgens in human umbilical artery smooth muscle," Clinical and Experimental Pharmacology and Physiology, vol. 40, no. 3, pp. 181-189, 2013.

[74] P. Tep-areenan, D. A. Kendall, and M. D. Randall, "Testosterone-induced vasorelaxation in the rat mesenteric arterial bed is mediated predominantly via potassium channels," British Journal of Pharmacology, vol. 135, no. 3, pp. 735-740, 2002.

[75] J. Espinoza, L. M. Montaño, and M. Perusquía, "Nongenomic bronchodilating action elicited by dehydroepiandrosterone (DHEA) in a guinea pig asthma model," The Journal of Steroid Biochemistry and Molecular Biology, vol. 138, pp. 174-182, 2013.

[76] J. Bordallo, M. J. García de Boto, C. Meana et al., "Modulatory role of endogenous androgens on airway smooth muscle tone in isolated guinea-pig and bovine trachea; involvement of $\beta_{2}$-adrenoceptors, the polyamine system and external calcium," European Journal of Pharmacology, vol. 601, no. 1-3, pp. 154-162, 2008.

[77] E. Flores-Soto, J. Reyes-García, A. Carbajal-García et al., “Sex steroids effects on Guinea pig airway smooth muscle tone and intracellular $\mathrm{Ca}^{2+}$ basal levels," Molecular and Cellular Endocrinology, vol. 439, pp. 444-456, 2017.

[78] V. Kouloumenta, A. Hatziefthimiou, E. Paraskeva, K. Gourgoulianis, and P. A. Molyvdas, "Non-genomic effect of testosterone on airway smooth muscle," British Journal of Pharmacology, vol. 149, no. 8, pp. 1083-1091, 2006.

[79] O. López-Canales, M. d. C. Castillo-Hernández, H. VargasRobles, A. Rios, J. López-Canales, and B. Escalante, “Androgens mediate $\beta$-adrenergic vasorelaxation impairment using adenylyl cyclase," Journal of Cardiovascular Pharmacology, vol. 71, no. 3, pp. 147-154, 2018.

[80] J. Brouillette, K. Rivard, E. Lizotte, and C. Fiset, "Sex and strain differences in adult mouse cardiac repolarization: importance of androgens," Cardiovascular Research, vol. 65, no. 1, pp. 148-157, 2005.

[81] K. Masuda, H. Takanari, M. Morishima et al., “Testosteronemediated upregulation of delayed rectifier potassium channel in cardiomyocytes causes abbreviation of QT intervals in rats," The Journal of Physiological Sciences, vol. 68, no. 6, pp. 759-767, 2018.

[82] L. J. DeLalio, A. S. Keller, J. Chen et al., "Interaction between pannexin 1 and caveolin-1 in smooth muscle can regulate blood pressure," Arteriosclerosis, Thrombosis, and Vascular Biology, vol. 38, no. 9, pp. 2065-2078, 2018.

[83] L. Wang, L. Sun, K. Wang et al., "Stimulation of epicardial sympathetic nerves at different sites induces cardiac electrical instability to various degrees," Scientific Reports, vol. 8, no. 1, p. 994, 2018.
[84] L.-K. Yang and Y.-X. Tao, "Physiology and pathophysiology of the $\beta_{3}$-adrenergic receptor," Progress in Molecular Biology and Translational Science, vol. 161, pp. 91-112, 2019.

[85] Y. Amrani and P. Bradding, " $\beta_{2}$-adrenoceptor function in asthma," Advances in Immunology, vol. 136, pp. 1-28, 2017.

[86] P. J. Barnes, "Adrenergic and non-adrenergic, non-cholinergic control of airways," Respiration, vol. 50, no. 2, pp. 9-16, 1986.

[87] S. Guimarães and D. Moura, "Vascular adrenoceptors: an update," Pharmacological Reviews, vol. 53, no. 2, pp. 319356, 2001.

[88] M. Philipp and L. Hein, "Adrenergic receptor knockout mice: distinct functions of 9 receptor subtypes," Pharmacology \& Therapeutics, vol. 101, no. 1, pp. 65-74, 2004.

[89] J. R. Docherty, "The pharmacology of $\alpha_{1}$-adrenoceptor subtypes," European Journal of Pharmacology, vol. 855, pp. 305-320, 2019.

[90] D. B. Bylund, "Subtypes of $\alpha_{1}$ - and $\alpha_{2}$-adrenergic receptors," The FASEB Journal, vol. 6, no. 3, pp. 832-839, 1992.

[91] B. Gebert-Oberle, J. Giles, S. Clayton, and Q.-K. Tran, "Calcium/calmodulin regulates signaling at the $\alpha^{1 \mathrm{~A}}$ adrenoceptor," European Journal of Pharmacology, vol. 848, pp. 70-79, 2019.

[92] L. D. Longo, N. Ueno, Y. Zhao, W. J. Pearce, and L. Zhang, "Developmental changes in $\alpha_{1}$-adrenergic receptors, $\mathrm{IP}_{3}$ responses, and NE-induced contraction in cerebral arteries," American Journal of Physiology-Heart and Circulatory Physiology, vol. 271, no. 6, pp. H2313-H2319, 1996.

[93] B. Ljung and A. Kjellstedt, "Functional antagonism of noradrenaline responses by felodipine and other calcium antagonists in vascular smooth muscles," Journal of Cardiovascular Pharmacology, vol. 10, no. 1, pp. S82-S88, 1987.

[94] M. H. Cobb, D. J. Robbins, and T. G. Boulton, "ERKs, extracellular signal-regulated MAP-2 kinases," Current Opinion in Cell Biology, vol. 3, no. 6, pp. 1025-1032, 1991.

[95] X. Jiao, P. J. Gonzalez-Cabrera, L. Xiao, M. E. Bradley, P. W. Abel, and W. B. Jeffries, "Tonic inhibitory role for cAMP in $\alpha_{1 \mathrm{a}}$-adrenergic receptor coupling to extracellular signal-regulated kinases 1/2," Journal of Pharmacology and Experimental Therapeutics, vol. 303, no. 1, pp. 247-256, 2002.

[96] B. A. Kenny, D. H. Chalmers, P. C. Philpott, and A. M. Naylor, "Characterization of an $\alpha_{1 \mathrm{D}}$-adrenoceptor mediating the contractile response of rat aorta to noradrenaline," British Journal of Pharmacology, vol. 115, no. 6, pp. 981-986, 1995.

[97] W. G. Lachnit, A. M. Tran, D. E. Clarke, and A. P. D. W. Ford, "Pharmacological characterization of an $\alpha_{1 \mathrm{~A}}$-adrenoceptor mediating contractile responses to noradrenaline in isolated caudal artery of rat," British Journal of Pharmacology, vol. 120, no. 5, pp. 819-826, 1997.

[98] L. Martinez, L. Carmona, and R. Villalobos-Molina, "Vascular $\alpha_{1 \mathrm{D}}$-adrenoceptor function is maintained during congestive heart failure after myocardial infarction in the rat," Archives of Medical Research, vol. 30, no. 4, pp. 290-297, 1999.

[99] G. A. Michelotti, D. T. Price, and D. A. Schwinn, " $\alpha_{1}$-adrenergic receptor regulation: basic science and clinical implications," Pharmacology \& Therapeutics, vol. 88, no. 3, pp. 281-309, 2000.

[100] C. J. Daly, C. Deighan, A. McGee et al., "A knockout approach indicates a minor vasoconstrictor role for vascular $\alpha_{1 \mathrm{~B}}$-adrenoceptors in mouse," Physiological Genomics, vol. 9, no. 2, pp. 85-91, 2002. 
[101] W. M. Chilian, "Functional distribution of $\alpha_{1^{-}}$and $\alpha_{2}$-adrenergic receptors in the coronary microcirculation," Circulation, vol. 84, no. 5, pp. 2108-2122, 1991.

[102] A. Tanoue, Y. Nasa, T. Koshimizu et al., "The $\alpha_{1 \mathrm{D}}$-adrenergic receptor directly regulates arterial blood pressure via vasoconstriction," Journal of Clinical Investigation, vol. 109, no. 6, pp. 765-775, 2002.

[103] L. Methven, P. Simpson, and J. McGrath, " $\alpha_{1 \mathrm{~A} / \mathrm{B}}-$ Knockout mice explain the native $\alpha_{1 \mathrm{D}}$-adrenoceptor's role in vasoconstriction and show that its location is independent of the other $\alpha_{1}$-subtypes," British Journal of Pharmacology, vol. 158, no. 7, pp. 1663-1675, 2009.

[104] C. Vecchione, L. Fratta, D. Rizzoni et al., "Cardiovascular influences of $\alpha_{1 \mathrm{~b}}$-adrenergic receptor defect in mice," Circulation, vol. 105, no. 14, pp. 1700-1707, 2002.

[105] L. Turnbull, D. T. McCloskey, T. D. O'Connell, P. C. Simpson, and A. J. Baker, " $\alpha_{1}$-adrenergic receptor responses in $\alpha_{1 \mathrm{AB}}-\mathrm{AR}$ knockout mouse hearts suggest the presence of $\alpha_{1 \mathrm{D}}-\mathrm{AR}$," American Journal of Physiology-Heart and Circulatory Physiology, vol. 284, no. 4, pp. H1104H1109, 2003.

[106] B. J. Everitt and K. D. Cairncross, "Adrenergic receptors in the guinea-pig trachea," Journal of Pharmacy and Pharmacology, vol. 21, no. 2, pp. 97-102, 1969.

[107] J. Fleisch, H. Maling, and B. Brodie, "Evidence for existence of alpha-adrenergic receptors in the mammalian trachea," American Journal of Physiology-Legacy Content, vol. 218, no. 2, pp. 596-599, 1970.

[108] M. P. Kneussl and J. B. Richardson, "Alpha-adrenergic receptors in human and canine tracheal and bronchial smooth muscle," Journal of Applied Physiology, vol. 45, no. 2, pp. 307-311, 1978.

[109] L. M. Montaño, M. Selman, and E. Hong, "Different effects of epinephrine on the Erythrocebus patas tracheal smooth muscle: predominance of $\alpha$-adrenergic receptors," Archivos de Investigacion Medica (Mexico), vol. 16, pp. 169-174, 1985.

[110] A. Cavalli, A.-L. Lattion, E. Hummler et al., "Decreased blood pressure response in mice deficient of the $\alpha_{1 \mathrm{~b}}$-adrenergic receptor," Proceedings of the National Academy of Sciences, vol. 94, no. 21, pp. 11589-11594, 1997.

[111] B. C. Jensen, T. D. O’Connell, and P. C. Simpson, “Alpha-1adrenergic receptors: targets for agonist drugs to treat heart failure," Journal of Molecular and Cellular Cardiology, vol. 51, no. 4, pp. 518-528, 2011.

[112] B. C. Jensen, P. M. Swigart, T. De Marco, C. Hoopes, and P. C. Simpson, " $\alpha_{1}$-adrenergic receptor subtypes in nonfailing and failing human myocardium," Circulation: Heart Failure, vol. 2, no. 6, pp. 654-663, 2009.

[113] S. Zhang, R. Takahashi, N. Yamashita, H. Teraoka, and T. Kitazawa, "Alpha ${ }_{1 \mathrm{~B}}$-adrenoceptor-mediated positive inotropic and positive chronotropic actions in the mouse atrium," European Journal of Pharmacology, vol. 839, pp. 82-88, 2018.

[114] A. Appert-Collin, S. Cotecchia, M. Nenniger-Tosato, T. Pedrazzini, and D. Diviani, "The A-kinase anchoring protein (AKAP)-Lbc-signaling complex mediates $\alpha_{1}$ adrenergic receptor-induced cardiomyocyte hypertrophy," Proceedings of the National Academy of Sciences, vol. 104, no. 24, pp. 10140-10145, 2007.

[115] K. Iwaki, V. P. Sukhatme, H. E. Shubeita, and K. R. Chien, " $\alpha$ - and $\beta$-adrenergic stimulation induces distinct patterns of immediate early gene expression in neonatal rat myocardial cells. fos/jun expression is associated with sarcomere assembly; Egr-1 induction is primarily an $\alpha_{1}$-mediated response," Journal of Biological Chemistry, vol. 265, pp. 13809-13817, 1990.

[116] K. U. Knowlton, M. C. Michel, M. Itani et al., "The $\alpha_{1 \mathrm{~A}^{-}}$ adrenergic receptor subtype mediates biochemical, molecular, and morphologic features of cultured myocardial cell hypertrophy," Journal of Biological Chemistry, vol. 268, pp. 15374-15380, 1993.

[117] M. T. Ramirez, V. P. Sah, X.-L. Zhao, J. J. Hunter, K. R. Chien, and J. H. Brown, "The MEKK-JNK pathway is stimulated by $\alpha_{1}$-adrenergic receptor and Ras activation and is associated within vitroandin vivo cardiac hypertrophy," Journal of Biological Chemistry, vol. 272, no. 22, pp. 14057-14061, 1997.

[118] R. S. Papay, T. Shi, M. T. Piascik, S. V. Naga Prasad, and D. M. Perez, " $\alpha_{1 \mathrm{~A}}$-adrenergic receptors regulate cardiac hypertrophy in vivo through interleukin-6 secretion," Molecular Pharmacology, vol. 83, no. 5, pp. 939-948, 2013.

[119] E. A. Woodcock, "Roles of $\alpha_{1 \mathrm{a}}$ and $\alpha_{1 \mathrm{~B}}$-adrenoceptors in heart: insights from studies of genetically modified mice," Clinical and Experimental Pharmacology and Physiology, vol. 34, no. 9, pp. 884-888, 2007.

[120] M. J. Zuscik, D. Chalothorn, D. Hellard et al., "Hypotension, autonomic failure, and cardiac hypertrophy in transgenic mice overexpressing the $\alpha_{1 \mathrm{~B}}$-adrenergic receptor," Journal of Biological Chemistry, vol. 276, no. 17, pp. 13738-13743, 2001.

[121] R. Aantaa, A. Marjamäki, and M. Scheinin, "Molecular pharmacology of $\alpha_{2}$-adrenoceptor subtypes," Annals of Medicine, vol. 27, no. 4, pp. 439-449, 1995.

[122] K. Aktories, G. Schultz, and K. H. Jakobs, "Islet-activating protein impairs $\alpha_{2}$-adrenoceptor-mediated inhibitory regulation of human platelet adenylate cyclase," NaunynSchmiedeberg's Archives of Pharmacology, vol. 324, no. 3, pp. 196-200, 1983.

[123] D. B. Bylund and C. Ray-Prenger, "Alpha-2A and alpha-2B adrenergic receptor subtypes: attenuation of cyclic AMP production in cell lines containing only one receptor subtype," The Journal of Pharmacology and Experimental Therapeutics, vol. 251, no. 2, pp. 640-644, 1989.

[124] A. Huhtinen, V. Hongisto, A. Laiho, E. Löyttyniemi, D. Pijnenburg, and M. Scheinin, "Gene expression profiles and signaling mechanisms in $\alpha_{2 \mathrm{~B}}$-adrenoceptor-evoked proliferation of vascular smooth muscle cells," BMC Systems Biology, vol. 11, no. 1, p. 65, 2017.

[125] N. L. Kanagy, " $\alpha_{2}$-adrenergic receptor signalling in hypertension,” Clinical Science, vol. 109, no. 5, pp. 431-437, 2005.

[126] Y. X. Wang, B. K. Fleischmann, and M. I. Kotlikoff, "M2 receptor activation of nonselective cation channels in smooth muscle cells: calcium and Gi/G(o) requirements," American Journal of Physiology-Cell Physiology, vol. 273, no. 2, pp. C500-C508, 1997.

[127] Y.-X. Wang and M. I. Kotlikoff, "Signalling pathway for histamine activation of non-selective cation channels in equine tracheal myocytes," The Journal of Physiology, vol. 523, no. 1, pp. 131-138, 2000.

[128] L. Birnbaumer, J. Abramowitz, A. Yatani et al., "Roles of G Proteins in coupling of receptors to ionic channels and other effector system," Critical Reviews in Biochemistry and Molecular Biology, vol. 25, no. 4, pp. 225-244, 1990.

[129] A. M. Brown, A. Yatani, J. Codina, and L. Birnbaumer, "Gating of atrial muscarinic $\mathrm{K}^{+}$channels by $\mathrm{G}$ proteins," Progress in Clinical and Biological Research, vol. 334, pp. 303-312, 1990.

[130] D. E. Berkowitz, D. T. Price, E. A. Bello, S. O. Page, and D. A. Schwinn, "Localization of messenger RNA for three 
distinct $\alpha_{2}$-adrenergic receptor subtypes in human tissues," Anesthesiology, vol. 81, no. 5, pp. 1235-1244, 1994.

[131] J. A. Giovannitti Jr., S. M. Thoms, and J. J. Crawford, “Alpha2 adrenergic receptor agonists: a review of current clinical applications," Anesthesia Progress, vol. 62, no. 1, pp. 31-38, 2015.

[132] G. Heusch, A. Deussen, J. Schipke, and V. Thämer, " $\alpha_{1}$ and $\alpha_{2}$-adrenoceptor-mediated vasoconstriction of large and small canine coronary arteries in vivo," Journal of Cardiovascular Pharmacology, vol. 6, no. 5, pp. 961-968, 1984.

[133] J. E. Faber, N. Yang, and X. Xin, "Expression of alphaadrenoceptor subtypes by smooth muscle cells and adventitial fibroblasts in rat aorta and in cell culture," The Journal of Pharmacology and Experimental Therapeutics, vol. 298, no. 2, pp. 441-452, 2001.

[134] C. M. Centurión, E. W. Willems, U. Arulmani, P. R. Saxena, D. Villalón, and L. F. Valdivia, " $5-\mathrm{HT}_{1 \mathrm{~B}}$ receptors and $\alpha_{2 \mathrm{~A} / 2 \mathrm{C}^{-}}$ adrenoceptors mediate external carotid vasoconstriction to dihydroergotamine," European Journal of Pharmacology, vol. 484, no. 2-3, pp. 287-290, 2004.

[135] E. W. Willems, L. F. Valdivia, P. R. Saxena, and C. M. Villalón, "The role of several $\alpha_{1}$ - and $\alpha_{2}$-adrenoceptor subtypes mediating vasoconstriction in the canine external carotid circulation," British Journal of Pharmacology, vol. 132, no. 6, pp. 1292-1298, 2001.

[136] M. Q. Paiva, M. Morato, D. Moura, and S. Guimarães, “A comparative study of postsynaptic $\alpha_{2}$-adrenoceptors of the dog mesenteric and rat femoral veins," Naunyn-Schmiedeberg's Archives of Pharmacology, vol. 360, no. 2, pp. 165-170, 1999.

[137] A. Yabuki, H. Higuchi, T. Yoshitomi et al., "Locally injected dexmedetomidine induces vasoconstriction via peripheral $\alpha-2 \mathrm{~A}$ adrenoceptor subtype in Guinea pigs," Regional Anesthesia and Pain Medicine, vol. 39, no. 2, pp. 133-136, 2014.

[138] A. Paris, M. Philipp, P. H. Tonner et al., "Activation of $\alpha_{2 B^{-}}$ adrenoceptors mediates the cardiovascular effects of etomidate," Anesthesiology, vol. 99, no. 4, pp. 889-895, 2003.

[139] R. E. Link, K. Desai, L. Hein et al., "Cardiovascular regulation in mice lacking $\alpha_{2}$-adrenergic receptor subtypes b and c," Science, vol. 273, no. 5276, pp. 803-805, 1996.

[140] A. V. Maltsev, E. V. Evdokimovskii, and Y. M. Kokoz, “ $\alpha_{2}$ adrenoceptor signaling in cardiomyocytes of spontaneously hypertensive rats starts to impair already at early age," Biochemical and Biophysical Research Communications, vol. 512, no. 4, pp. 908-913, 2019.

[141] A. V. Maltsev, Y. M. Kokoz, E. V. Evdokimovskii, O. Y. Pimenov, S. Reyes, and A. E. Alekseev, "Alpha-2 adrenoceptors and imidazoline receptors in cardiomyocytes mediate counterbalancing effect of agmatine on NO synthesis and intracellular calcium handling," Journal of Molecular and Cellular Cardiology, vol. 68, pp. 66-74, 2014.

[142] Y. Tanaka, T. Horinouchi, and K. Koike, "New insights into $\beta$-adrenoceptors in smooth muscle: distribution of receptor subtypes and molecular mechanisms triggering muscle relaxation," Clinical and Experimental Pharmacology and Physiology, vol. 32, no. 7, pp. 503-514, 2005.

[143] G. Kayki Mutlu, E. Arioglu Inan, I. Karaomerlioglu et al., "Role of the $\beta_{3}$-adrenergic receptor subtype in catecholamine-induced myocardial remodeling," Molecular and Cellular Biochemistry, vol. 446, no. 1-2, pp. 149-160, 2018.

[144] C. Nahmias, N. Blin, J. M. Elalouf, M. G. Mattei, A. D. Strosberg, and L. J. Emorine, "Molecular characterization of the mouse $\beta_{3}$-adrenergic receptor: relationship with the atypical receptor of adipocytes," The EMBO Journal, vol. 10, no. 12, pp. 3721-3727, 1991.

[145] T. L. Yang-Feng, F. Y. Xue, W. W. Zhong et al., "Chromosomal organization of adrenergic receptor genes," Proceedings of the National Academy of Sciences, vol. 87, no. 4, pp. 1516-1520, 1990.

[146] Z. Sun, D. Hou, S. Liu, W. Fu, J. Wang, and Z. Liang, "Norepinephrine inhibits the cytotoxicity of NK92MI cells via the $\beta_{2}$-adrenoceptor/cAMP/PKA/pCREB signaling pathway," Molecular Medicine Reports, vol. 17, pp. 85308535, 2018.

[147] Y. Y. Zhou, H. Cheng, K. Y. Bogdanov et al., "Localized cAMP-dependent signaling mediates $\beta_{2}$-adrenergic modulation of cardiac excitation-contraction coupling," American Journal of Physiology-Heart and Circulatory Physiology, vol. 273, no. 3, pp. H1611-H1618, 1997.

[148] R. Begonha, D. Moura, and S. Guimarães, "Vascular $\beta$-adrenoceptor-mediated relaxation and the tone of the tissue in canine arteries," Journal of Pharmacy and Pharmacology, vol. 47, no. 6, pp. 510-513, 1995.

[149] L. Edvinsson and C. Owman, "Pharmacological characterization of adrenergic alpha and beta receptors mediating the vasomotor responses of cerebral arteries Ir vitro," Circulation Research, vol. 35, no. 6, pp. 835-849, 1974.

[150] S. R. O'Donnell and J. C. Wanstall, "Responses to the $\beta_{2^{-}}$ selective agonist procaterol of vascular and atrial preparations with different functional beta-adrenoceptor populations," British Journal of Pharmacology, vol. 84, pp. 227-235, 1985.

[151] C. L. Moore, S. J. McClenahan, H. M. Hanvey et al., "Beta1adrenergic receptor-mediated dilation of rat cerebral artery requires shaker-type $\mathrm{K}_{\mathrm{V}} 1$ channels on PSD95 scaffold," Journal of Cerebral Blood Flow \& Metabolism, vol. 35, no. 9, pp. 1537-1546, 2015.

[152] Z.-Y. Zhou, W.-R. Zhao, W.-T. Shi et al., "Endothelial-dependent and independent vascular relaxation effect of tetrahydropalmatine on rat aorta," Frontiers in Pharmacology, vol. 10, p. 336, 2019.

[153] D. A. Deshpande, B. S. Theriot, R. B. Penn, and J. K. L. Walker, " $\beta$-arrestins specifically constrain $\beta_{2}$-adrenergic receptor signaling and function in airway smooth muscle," The FASEB Journal, vol. 22, no. 7, pp. 2134-2141, 2008.

[154] T. J. Torphy, " $\beta$-adrenoceptors, cAMP and airway smooth muscle relaxation: challenges to the dogma," Trends in Pharmacological Sciences, vol. 15, no. 10, pp. 370-374, 1994.

[155] S. R. Agarwal, C. Fiore, K. Miyashiro, R. S. Ostrom, and R. D. Harvey, "Effect of adenylyl cyclase type 6 on localized production of cAMP by $\beta_{2}$ adrenoceptors in human airway smooth-muscle cells," Journal of Pharmacology and Experimental Therapeutics, vol. 370, no. 1, pp. 104-110, 2019.

[156] M. Johnson, "Molecular mechanisms of $\beta_{2}$-adrenergic receptor function, response, and regulation," Journal of Allergy and Clinical Immunology, vol. 117, no. 1, pp. 18-24, 2006.

[157] Y. Chen, B. Guo, H. Zhang, L. Hu, and J. Wang, "Higenamine, a dual agonist for $\beta_{1^{-}}$and $\beta_{2}$-adrenergic receptors identified by screening a traditional Chinese medicine library," Planta Medica, vol. 85, no. 9-10, pp. 738-744, 2019.

[158] M. J. Lohse, S. Engelhardt, and T. Eschenhagen, "What is the role of $\beta$-adrenergic signaling in heart failure?" Circulation Research, vol. 93, no. 10, pp. 896-906, 2003.

[159] R. C. Spadari, C. Cavadas, A. E. T. S. de Carvalho, D. Ortolani, A. L. de Moura, and P. F. Vassalo, "Role of betaadrenergic receptors and sirtuin signaling in the heart during 
aging, heart failure, and adaptation to stress," Cellular and Molecular Neurobiology, vol. 38, no. 1, pp. 109-120, 2018.

[160] A. Y.-H. Woo, Y. Song, R.-P. Xiao, and W. Zhu, "Biased $\beta_{2^{-}}$ adrenoceptor signalling in heart failure: pathophysiology and drug discovery," British Journal of Pharmacology, vol. 172, no. 23, pp. 5444-5456, 2015.

[161] Y. Daaka, L. M. Luttrell, and R. J. Lefkowitz, "Switching of the coupling of the $\beta_{2}$-adrenergic receptor to different $G$ proteins by protein kinase A," Nature, vol. 390, no. 6655, pp. 88-91, 1997.

[162] M. J. Strohman et al., "Local membrane charge regulates $\beta_{2}$ adrenergic receptor coupling to $\mathrm{Gi}_{3}$," Nature Communications, vol. 10, p. 2234, 2019.

[163] J. Sun, L. Fu, X. Tang et al., "Testosterone modulation of cardiac $\beta$-adrenergic signals in a rat model of heart failure," General and Comparative Endocrinology, vol. 172, no. 3, pp. 518-525, 2011.

[164] M. M. McConnaughey and S. G. Iams, "Sex hormones change adrenoceptors in blood vessels of the spontaneously hypertensive rat," Clinical and Experimental Hypertension, vol. 15, no. 1, pp. 153-170, 1993.

[165] M. P. Walsh, "Regulation of vascular smooth muscle tone," Canadian Journal of Physiology and Pharmacology, vol. 72, no. 8, pp. 919-936, 1994.

[166] Y. C. Loh, "Overview of the microenvironment of vasculature in vascular tone regulation," International Journal of Molecular Sciences, vol. 19, no. 1, p. 120, 2018.

[167] D. Ghosh, A. U. Syed, M. P. Prada et al., "Calcium channels in vascular smooth muscle," Advances in Pharmacology, vol. 78, pp. 49-87, 2017.

[168] W. F. Jackson, "Ion channels and vascular tone," Hypertension, vol. 35, no. 1, pp. 173-178, 2000.

[169] X.-Q. Hu and L. Zhang, "Function and regulation of large conductance $\mathrm{Ca}^{2+}$-activated $\mathrm{K}^{+}$channel in vascular smooth muscle cells," Drug Discovery Today, vol. 17, no. 17-18, pp. 974-987, 2012.

[170] W. F. Jackson, " $K_{V}$ channels and the regulation of vascular smooth muscle tone," Microcirculation, vol. 25, no. 1, Article ID e12421, 2018.

[171] A. P. Somlyo and B. Himpens, "Cell calcium and its regulation in smooth muscle," The FASEB Journal, vol. 3, no. 11, pp. 2266-2276, 1989.

[172] O. K. Dagher, M. A. Jaffa, A. Habib, F. N. Ziyadeh, and A. A. Jaffa, "Heteromerization fingerprints between bradykinin B2 and thromboxane TP receptors in native cells," PLoS One, vol. 14, no. 5, Article ID e0216908, 2019.

[173] D. J. Miller and A. O’Dowd, "Vascular smooth muscle actions of carnosine as its zinc complex are mediated by histamine $\mathrm{H}_{1}$ and $\mathrm{H}_{2}$ receptors," Biochemistry (Mosc), vol. 65, pp. 798-806, 2000.

[174] K. P. Minneman and T. A. Esbenshade, " $\alpha_{1}$-adrenergic receptor subtypes," Annual Review of Pharmacology and Toxicology, vol. 34, no. 1, pp. 117-133, 1994.

[175] W. E. Schutzer and S. L. Mader, "Age-related changes in vascular adrenergic signaling: clinical and mechanistic implications," Ageing Research Reviews, vol. 2, no. 2, pp. 169-190, 2003.

[176] C. D. Benham, P. Hess, and R. W. Tsien, "Two types of calcium channels in single smooth muscle cells from rabbit ear artery studied with whole-cell and single-channel recordings," Circulation Research, vol. 61, no. 4, pp. I10-I16, 1987.

[177] Z. Liu and R. A. Khalil, "Evolving mechanisms of vascular smooth muscle contraction highlight key targets in vascular disease," Biochemical Pharmacology, vol. 153, pp. 91-122, 2018.

[178] W. A. Large, "Receptor-operated $\mathrm{Ca}^{2+}$-permeable nonselective cation channels in vascular smooth muscle: a physiologic perspective," Journal of Cardiovascular Electrophysiology, vol. 13, no. 5, pp. 493-501, 2002.

[179] F. P. Leung, L. M. Yung, X. Yao, I. Laher, and Y. Huang, "Store-operated calcium entry in vascular smooth muscle," British Journal of Pharmacology, vol. 153, no. 5, pp. 846-857, 2008.

[180] M. Malczyk, A. Erb, C. Veith et al., "The role of transient receptor potential channel 6 channels in the pulmonary vasculature," Frontiers in Immunology, vol. 8, p. 707, 2017.

[181] A. Martinsen, C. Dessy, and N. Morel, "Regulation of calcium channels in smooth muscle: new insights into the role of myosin light chain kinase," Channels, vol. 8, no. 5, pp. 402-413, 2014.

[182] M. Lorigo, M. Mariana, J. Feiteiro, and E. Cairrao, "How is the human umbilical artery regulated?" Journal of Obstetrics and Gynaecology Research, vol. 44, no. 7, pp. 1193-1201, 2018.

[183] N. L. McDaniel, C. M. Rembold, and R. A. Murphy, "Cyclic nucleotide dependent relaxation in vascular smooth muscle," Canadian Journal of Physiology and Pharmacology, vol. 72, no. 11, pp. 1380-1385, 1994.

[184] Y. Dohi, M. Kojima, K. Sato, and T. F. Lüscher, "Age-related changes in vascular smooth muscle and endothelium," Drugs \& Aging, vol. 7, no. 4, pp. 278-291, 1995.

[185] A. P. Somlyo and A. V. Somlyo, "Signal transduction and regulation in smooth muscle," Nature, vol. 372 , no. 6503 , pp. 231-236, 1994.

[186] M. Perusquía, R. Hernández, M. A. Morales, M. G. Campos, and C. M. Villalón, "Role of endothelium in the vasodilating effect of progestins and androgens on the rat thoracic aorta," General Pharmacology: The Vascular System, vol. 27, no. 1, pp. 181-185, 1996.

[187] V. P. Deenadayalu, R. E. White, J. N. Stallone, X. Gao, and A. J. Garcia, "Testosterone relaxes coronary arteries by opening the large-conductance, calcium-activated potassium channel," American Journal of Physiology-Heart and Circulatory Physiology, vol. 281, no. 4, pp. H1720-H1727, 2001.

[188] P. Yue, K. Chatterjee, C. Beale, P. A. Poole-Wilson, and P. Collins, "Testosterone relaxes rabbit coronary arteries and aorta," Circulation, vol. 91, no. 4, pp. 1154-1160, 1995.

[189] T. M. Chou, K. Sudhir, S. J. Hutchison et al., "Testosterone induces dilation of canine coronary conductance and resistance arteries in vivo," Circulation, vol. 94, no. 10, pp. 2614-2619, 1996.

[190] H. Honda, T. Unemoto, and H. Kogo, "Different mechanisms for testosterone-induced relaxation of aorta between normotensive and spontaneously hypertensive rats," $\mathrm{Hy}$ pertension, vol. 34, no. 6, pp. 1232-1236, 1999.

[191] O. Yildiz, M. Seyrek, H. Gul et al., "Testosterone relaxes human internal mammary artery in vitro," Journal of Cardiovascular Pharmacology, vol. 45, no. 6, pp. 580-585, 2005.

[192] J. F. Reckelhoff, "Gender differences in the regulation of blood pressure," Hypertension, vol. 37, no. 5, pp. 1199-1208, 2001.

[193] C. Delles and G. Currie, "Sex differences in hypertension and other cardiovascular diseases," Journal of Hypertension, vol. 36, no. 4, pp. 768-770, 2018.

[194] A. L. Beale, P. Meyer, T. H. Marwick, C. S. P. Lam, and D. M. Kaye, "Sex differences in cardiovascular pathophysiology," Circulation, vol. 138, no. 2, pp. 198-205, 2018. 
[195] M. Volpe, G. Gallo, A. Battistoni, and G. Tocci, "Highlights of ESC/ESH 2018 guidelines on the management of hypertension: what every doctor should know," High Blood Pressure \& Cardiovascular Prevention, vol. 26, no. 1, pp. 1-8, 2019.

[196] M.-A. Devynck, "Gender and vascular smooth muscle cells," Journal of Hypertension, vol. 20, no. 11, pp. 2139-2140, 2002.

[197] I. P. Torres, M. E. Hafidi, J. Zamora-González, O. Infante, R. Chavira, and G. Baños, "Modulation of aortic vascular reactivity by sex hormones in a male rat model of metabolic syndrome," Life Sciences, vol. 80, no. 23, pp. 2170-2180, 2007.

[198] C. Jenkins, R. Salisbury, and D. Ely, "Castration lowers and testosterone restores blood pressure in several rat strains on high sodium diets," Clinical and Experimental Hypertension, vol. 16, no. 5, pp. 611-625, 1994.

[199] R. Bentley-Lewis, E. Seely, and A. Dunaif, "Ovarian hypertension: polycystic ovary syndrome," Endocrinology and Metabolism Clinics of North America, vol. 40, no. 2, pp. 433-449, 2011.

[200] P. Pinola, K. Puukka, T. T. Piltonen et al., "Normo- and hyperandrogenic women with polycystic ovary syndrome exhibit an adverse metabolic profile through life," Fertility and Sterility, vol. 107, no. 3, pp. 788-795, 2017.

[201] T. Rocha, R. P. Crespo, V. V. R. Yance et al., "Persistent poor metabolic profile in postmenopausal women with ovarian hyperandrogenism after testosterone level normalization," Journal of the Endocrine Society, vol. 3, no. 5, pp. 1087-1096, 2019.

[202] M. C. Markopoulos, E. Kassi, K. I. Alexandraki, G. Mastorakos, and G. Kaltsas, "Management of endocrine disease: hyperandrogenism after menopause," European Journal of Endocrinology, vol. 172, no. 2, pp. R79-R91, 2015.

[203] M. Nagamani, C. Osuampke, and M. E. Kelver, "Increased bioactive luteinizing hormone levels and bio/immuno ratio in women with hyperthecosis of the ovaries: possible role of hyperinsulinemia," The Journal of Clinical Endocrinology \& Metabolism, vol. 84, no. 5, pp. 1685-1689, 1999.

[204] L. S. Morgan, "Hormonally active gynecologic tumors," Seminars in Surgical Oncology, vol. 6, no. 2, pp. 83-90, 1990.

[205] R. S. Legro, S. A. Arslanian, D. A. Ehrmann et al., "Diagnosis and treatment of polycystic ovary syndrome: an endocrine society clinical practice guideline," The Journal of Clinical Endocrinology \& Metabolism, vol. 98, no. 12, pp. 4565-4592, 2013.

[206] D. A. Ehrmann, "Polycystic ovary syndrome," New England Journal of Medicine, vol. 352, no. 12, pp. 1223-1236, 2005.

[207] M.-J. Chen, W.-S. Yang, J.-H. Yang, C.-L. Chen, H.-N. Ho, and Y.-S. Yang, "Relationship between androgen levels and blood pressure in young women with polycystic ovary syndrome," Hypertension, vol. 49, no. 6, pp. 1442-1447, 2007.

[208] P. J. Scarpace, N. Tumer, and S. L. Mader, " $\beta$-adrenergic function in aging," Drugs \& Aging, vol. 1, no. 2, pp. 116-129, 1991.

[209] S. R. O'Donnell and J. C. Wanstall, "Thyroxine treatment of aged or young rats demonstrates that vascular responses mediated by $\beta$-adrenoceptor subtypes can be differentially regulated," British Journal of Pharmacology, vol. 88, no. 1, pp. 41-49, 1986.

[210] O. R. Stephens, K. Weiss, M. Frimel et al., "Interdependence of hypoxia and $\beta$-adrenergic receptor signaling in pulmonary arterial hypertension," American Journal of Physiology-Lung Cellular and Molecular Physiology, vol. 317, no. 3, pp. L369-L380, 2019.
[211] D. S. Martin, S. Biltoft, R. Redetzke, and E. Vogel, "Castration reduces blood pressure and autonomic venous tone in male spontaneously hypertensive rats," Journal of $\mathrm{Hy}$ pertension, vol. 23, no. 12, pp. 2229-2236, 2005.

[212] M. Sakaue and B. B. Hoffman, "Glucocorticoids induce transcription and expression of the $\alpha 1 \mathrm{~B}$ adrenergic receptor gene in DTT1 MF-2 smooth muscle cells," Journal of Clinical Investigation, vol. 88, no. 2, pp. 385-389, 1991.

[213] T. Saruta, H. Suzuki, M. Handa, Y. Igarashi, K. Kondo, and S. Senba, "Multiple factors contribute to the pathogenesis of hypertension in Cushing's syndrome," The Journal of Clinical Endocrinology \& Metabolism, vol. 62, no. 2, pp. 275-279, 1986.

[214] S. Al-Gburi, A. Deussen, B. Zatschler et al., "Sex-difference in expression and function of beta-adrenoceptors in macrovessels: role of the endothelium," Basic Research in Cardiology, vol. 112, no. 3, p. 29, 2017.

[215] K. Riedel, A. J. Deussen, J. Tolkmitt et al., "Estrogen determines sex differences in adrenergic vessel tone by regulation of endothelial $\beta$-adrenoceptor expression," American Journal of Physiology-Heart and Circulatory Physiology, vol. 317, no. 2, pp. H243-H254, 2019.

[216] M. Lam, E. Lamanna, and J. E. Bourke, "Regulation of airway smooth muscle contraction in health and disease," Advances in Experimental Medicine and Biology, vol. 1124, pp. 381-422, 2019.

[217] B. Bazán-Perkins, E. Flores-Soto, C. Barajas-Lopez, and L. M. Montaño, "Role of sarcoplasmic reticulum $\mathrm{Ca}^{2+}$ content in $\mathrm{Ca}^{2+}$ entry of bovine airway smooth muscle cells," Naunyn-Schmiedeberg's Archives of Pharmacology, vol. 368, pp. 277-283, 2003.

[218] L. M. Montaño, V. Carbajal, J. L. Arreola, C. Barajas-López, E. Flores-Soto, and M. H. Vargas, "Acetylcholine and tachykinins involvement in the caffeine-induced biphasic change in intracellular $\mathrm{Ca}^{2+}$ in bovine airway smooth muscle," British Journal of Pharmacology, vol. 139, no. 6, pp. 1203-1211, 2003.

[219] J. Reyes-García, E. Flores-Soto, A. Carbajal-García, B. Sommer, and L. M. Montaño, "Maintenance of intracellular $\mathrm{Ca}^{2+}$ basal concentration in airway smooth muscle," International Journal of Molecular Medicine, vol. 42, pp. 2998-3008, 2018.

[220] M. J. Berridge, "Inositol trisphosphate and calcium signalling,” Nature, vol. 361, no. 6410, pp. 315-325, 1993.

[221] Q.-H. Liu, Y.-M. Zheng, A. S. Korde et al., "Protein kinase $\mathrm{C}-\varepsilon$ regulates local calcium signaling in airway smooth muscle cells," American Journal of Respiratory Cell and Molecular Biology, vol. 40, no. 6, pp. 663-671, 2009.

[222] R. ZhuGe, S. M. Sims, R. A. Tuft, K. E. Fogarty, and J. V. Walsh Jr., "Ca ${ }^{2+}$ sparks activate $\mathrm{K}^{+}$and $\mathrm{Cl}^{-}$channels, resulting in spontaneous transient currents in Guinea-pig tracheal myocytes," The Journal of Physiology, vol. 513, no. 3, pp. 711-718, 1998.

[223] K. Mahn, S. J. Hirst, S. Ying et al., "Diminished sarco/endoplasmic reticulum $\mathrm{Ca}^{2+}$ ATPase (SERCA) expression contributes to airway remodelling in bronchial asthma," Proceedings of the National Academy of Sciences, vol. 106, no. 26, pp. 10775-10780, 2009.

[224] Y.-f. Chen, J. Cao, J.-n. Zhong et al., "Plasma membrane $\mathrm{Ca}^{2+}$-ATPase regulates $\mathrm{Ca}^{2+}$ signaling and the proliferation of airway smooth muscle cells," European Journal of Pharmacology, vol. 740, pp. 733-741, 2014.

[225] G. P. Anderson, "Current issues with $\beta_{2}$-adrenoceptor agonists: pharmacology and molecular and cellular 
mechanisms," Clinical Reviews in Allergy \& Immunology, vol. 31, pp. 119-130, 2006.

[226] P. Campos-Bedolla, M. Vargas, E. Calixto et al., "Alphamethyl-5-HT, a 5- $\mathrm{HT}_{2}$ receptor agonist, stimulates $\beta_{2^{-}}$ adrenoceptors in Guinea pig airway smooth muscle," Pharmacological Research, vol. 54, no. 6, pp. 468-473, 2006.

[227] S. Adda, B. K. Fleischmann, B. D. Freedman, M.-f. Yu, D. W. P. Hay, and M. I. Kotlikoff, "Expression and function of voltage-dependent potassium channel genes in human airway smooth muscle," Journal of Biological Chemistry, vol. 271, no. 22, pp. 13239-13243, 1996.

[228] L. M. Montaño, J. E. Cruz-Valderrama, A. Figueroa et al., "Characterization of $\mathrm{P} 2 \mathrm{Y}$ receptors mediating ATP induced relaxation in Guinea pig airway smooth muscle: involvement of prostaglandins and $\mathrm{K}^{+}$channels," Pflügers Archiv-European Journal of Physiology, vol. 462, no. 4, pp. 573-585, 2011.

[229] M. Feletou, "Calcium-activated potassium channels and endothelial dysfunction: therapeutic options?" British Journal of Pharmacology, vol. 156, no. 4, pp. 545-562, 2009.

[230] Z. W. Wang and M. I. Kotlikoff, "Activation of $\mathrm{K}_{\mathrm{Ca}}$ channels in airway smooth muscle cells by endogenous protein kinase A," American Journal of Physiology-Lung Cellular and Molecular Physiology, vol. 271, pp. L100-L105, 1996.

[231] L. I. Brueggemann, L. Cribbs, J. Schwartz, M. Wang, A. Kouta, and K. Byron, "Mechanisms of PKA-dependent potentiation of Kv7.5 channel activity in human airway smooth muscle cells," International Journal of Molecular Sciences, vol. 19, no. 8, 2018.

[232] B. Kjellman and P. M. Gustafsson, "Asthma from childhood to adulthood: asthma severity, allergies, sensitization, living conditions, gender influence and social consequences," Respiratory Medicine, vol. 94, pp. 454-465, 2000.

[233] R. de Marco, F. Locatelli, J. Sunyer, and P. Burney, "Differences in incidence of reported asthma related to age in men and women. A retrospective analysis of the data of the European respiratory health survey," American Journal of Respiratory and Critical Care Medicine, vol. 162, no. 1, pp. $68-74,2000$.

[234] M. Schatz, K. Harden, A. Forsythe et al., "The course of asthma during pregnancy, post partum, and with successive pregnancies: a prospective analysis," Journal of Allergy and Clinical Immunology, vol. 81, no. 3, pp. 509-517, 1988.

[235] R. J. Troisi, F. E. Speizer, W. C. Willett, D. Trichopoulos, and B. Rosner, "Menopause, postmenopausal estrogen preparations, and the risk of adult-onset asthma. A prospective cohort study," American Journal of Respiratory and Critical Care Medicine, vol. 152, no. 4, pp. 1183-1188, 1995.

[236] J. L. Zimmerman, P. G. Woodruff, S. Clark, and C. A. Camargo, "Relation between phase of menstrual cycle and emergency department visits for acute asthma," American Journal of Respiratory and Critical Care Medicine, vol. 162 , no. 2 , pp. $512-515,2000$.

[237] J. V. Fahy, "Type 2 inflammation in asthma--present in most, absent in many," Nature Reviews Immunology, vol. 15, no. 1, pp. 57-65, 2015.

[238] B. N. Lambrecht and H. Hammad, "The immunology of asthma," Nature Immunology, vol. 16, pp. 45-56, 2015.

[239] S. Laffont, E. Blanquart, and J. C. Guery, "Sex differences in asthma: a key role of androgen-signaling in group 2 innate lymphoid cells," Frontiers in Immunology, vol. 8, p. 1069, 2017.

[240] H. Fuseini, J. A. Yung, J. Yvonne Cephus et al., "Testosterone decreases house dust mite-induced type 2 and IL-17A- mediated airway inflammation," The Journal of Immunology, vol. 201, no. 7, pp. 1843-1854, 2018.

[241] C. K. Billington, R. B. Penn, and I. P. Hall, " $\beta_{2}$ agonists," Handbook of Experimental Pharmacology, vol. 237, pp. 2340, 2017.

[242] P. J. Salt and L. L. Iverson, "Inhibition of the extraneuronal uptake of catecholamine in the isolated rat heart by cholesterol," Nature New Biology, vol. 238, no. 81, pp. 91-92, 1972.

[243] P. S. Foster, R. G. Goldie, and J. W. Paterson, "Effect of steroids on $\beta$-adrenoceptor-mediated relaxation of pig bronchus," British Journal of Pharmacology, vol. 78, no. 2, pp. 441-445, 1983.

[244] J. A. Armour, "Physiology of the intrinsic cardiac nervous system," Heart Rhythm, vol. 8, no. 5, p. 739, 2011.

[245] D. D. Gibbons, E. Marie Southerland, D. B. Hoover, E. Beaumont, J. Andrew Armour, and J. L. Ardell, "Neuromodulation targets intrinsic cardiac neurons to attenuate neuronally mediated atrial arrhythmias," American Journal of Physiology-Regulatory, Integrative and Comparative Physiology, vol. 302, no. 3, pp. R357-R364, 2012.

[246] E. Wake and K. Brack, "Characterization of the intrinsic cardiac nervous system," Autonomic Neuroscience, vol. 199, pp. 3-16, 2016.

[247] D. H. Pauza, V. Skripka, N. Pauziene, and R. Stropus, "Morphology, distribution, and variability of the epicardiac neural ganglionated subplexuses in the human heart," The Anatomical Record, vol. 259, no. 4, pp. 353-382, 2000.

[248] G. W. Thompson, K. Collier, J. L. Ardell, G. Kember, and J. A. Armour, "Functional interdependence of neurons in a single canine intrinsic cardiac ganglionated plexus," The Journal of Physiology, vol. 528, no. 3, pp. 561-571, 2000.

[249] J. A. Armour, M. H. Huang, and F. M. Smith, "Peptidergic modulation of in situ canine intrinsic cardiac neurons," Peptides, vol. 14, no. 2, pp. 191-202, 1993.

[250] I. Y. Kuo and B. E. Ehrlich, "Signaling in muscle contraction," Cold Spring Harbor Perspectives in Biology, vol. 7, Article ID a006023, 2015.

[251] P. P. Jones, W. Guo, and S. R. W. Chen, "Control of cardiac ryanodine receptor by sarcoplasmic reticulum luminal $\mathrm{Ca}^{2+}, "$ The Journal of General Physiology, vol. 149, pp. 867-875, 2017.

[252] L. Hove-Madsen and D. M. Bers, "Sarcoplasmic reticulum $\mathrm{Ca}^{2+}$ uptake and thapsigargin sensitivity in permeabilized rabbit and rat ventricular myocytes," Circulation Research, vol. 73, no. 5, pp. 820-828, 1993.

[253] J. W. Bassani, R. A. Bassani, and D. M. Bers, "Relaxation in rabbit and rat cardiac cells: species-dependent differences in cellular mechanisms," The Journal of Physiology, vol. 476, no. 2, pp. 279-293, 1994.

[254] B. L. Gerhardstein, T. S. Puri, A. J. Chien, and M. M. Hosey, "Identification of the sites phosphorylated by cyclic AMPdependent protein kinase on the $\beta_{2}$ subunit of L-type voltage-dependent calcium channels," Biochemistry, vol. 38, no. 32, pp. 10361-10370, 1999.

[255] S. O. Marx, S. Reiken, Y. Hisamatsu et al., "PKA phosphorylation dissociates FKBP12.6 from the calcium release channel (ryanodine receptor): defective regulation in failing hearts," Cell, vol. 101, no. 4, pp. 365-376, 2000.

[256] H. K. Simmerman and L. R. Jones, "Phospholamban: protein structure, mechanism of action, and role in cardiac function," Physiological Reviews, vol. 78, no. 4, pp. 921-947, 1998.

[257] C. Gauthier, G. Tavernier, F. Charpentier, D. Langin, and H. Le Marec, "Functional $\beta_{3}$-adrenoceptor in the human 
heart," Journal of Clinical Investigation, vol. 98, pp. 556-562, 1996.

[258] W. Z. Zhu, M. Zheng, W. J. Koch, R. J. Lefkowitz, B. K. Kobilka, and R.-P. Xiao, "Dual modulation of cell survival and cell death by $\beta_{2}$-adrenergic signaling in adult mouse cardiac myocytes," Proceedings of the National Academy of Sciences of the USA, vol. 98, no. 4, pp. 1607-1612, 2001.

[259] K. L. Golden, J. D. Marsh, and Y. Jiang, "Testosterone regulates mRNA levels of calcium regulatory proteins in cardiac myocytes," Hormone and Metabolic Research, vol. 36, no. 4, pp. 197-202, 2004.

[260] W. A. Catterall, E. Perez-Reyes, T. P. Snutch, and J. Striessnig, "International union of pharmacology. XLVIII. Nomenclature and structure-function relationships of voltage-gated calcium channels," Pharmacological Reviews, vol. 57, no. 4, pp. 411-425, 2005.

[261] Y. N. Andrade, J. Fernandes, I. M. Lorenzo, M. Arniges, and M. A. Valverde, TRP Ion Channel Function in Sensory Transduction and Cellular Signaling Cascades, W. B. Liedtke and S. Heller, Eds., CRC Press, Boca Raton, FL, USA, 2007.

[262] G. Michels, F. Er, M. Eicks, S. Herzig, and U. C. Hoppe, "Long-term and immediate effect of testosterone on single T-type calcium channel in neonatal rat cardiomyocytes," Endocrinology, vol. 147, pp. 5160-5169, 2006.

[263] J. M. Vicencio, C. Ibarra, M. Estrada et al., "Testosterone induces an intracellular calcium increase by a nongenomic mechanism in cultured rat cardiac myocytes," Endocrinology, vol. 147, no. 3, pp. 1386-1395, 2006.

[264] J. L. Boyer, S. G. Graber, G. L. Waldo, T. K. Harden, and J. C. Garrison, "Selective activation of phospholipase $C$ by recombinant G-protein $\alpha$ - and $\beta \gamma$-subunits," Journal of Biological Chemistry, vol. 269, pp. 2814-2819, 1994.

[265] S. R. Neves, P. T. Ram, and R. Iyengar, "G protein pathways," Science, vol. 296, pp. 1636-1639, 2002.

[266] F. Er, G. Michels, M. C. Brandt et al., "Impact of testosterone on cardiac L-type calcium channels and $\mathrm{Ca}^{2+}$ sparks: acute actions antagonize chronic effects," Cell Calcium, vol. 41, no. 5, pp. 467-477, 2007.

[267] E. D. Luczak and L. A. Leinwand, "Sex-based cardiac physiology," Annual Review of Physiology, vol. 71, no. 1, pp. 1-18, 2009.

[268] A. Elagizi, T. S. Kohler, and C. J. Lavie, "Testosterone and cardiovascular health," Mayo Clinic Proceedings, vol. 93, no. 1, pp. 83-100, 2018.

[269] B. Desroches, T. P. Kohn, C. Welliver, and A. W. Pastuszak, "Testosterone therapy in the new era of Food and Drug Administration oversight," Translational Andrology and Urology, vol. 5, no. 2, pp. 207-212, 2016.

[270] N. K. LeBrasseur, N. Lajevardi, R. Miciek, N. Mazer, T. W. Storer, and S. Bhasin, "Effects of testosterone therapy on muscle performance and physical function in older men with mobility limitations (the TOM trial): design and methods," Contemporary Clinical Trials, vol. 30, no. 2, pp. 133-140, 2009.

[271] C. J. Crandall and E. Barrett-Connor, "Endogenous sex steroid levels and cardiovascular disease in relation to the menopause: a systematic review," Endocrinology and Metabolism Clinics of North America, vol. 42, no. 2, pp. 227-253, 2013.

[272] M. A. Maturana, V. Breda, F. Lhullier, and P. M. Spritzer, "Relationship between endogenous testosterone and cardiovascular risk in early postmenopausal women," Metabolism, vol. 57, no. 7, pp. 961-965, 2008.
[273] K. Sutton-Tyrrell, R. P. Wildman, K. A. Matthews et al., "Sexhormone-binding globulin and the free androgen index are related to cardiovascular risk factors in multiethnic premenopausal and perimenopausal women enrolled in the Study of Women across the Nation (SWAN)," Circulation, vol. 111, no. 10, pp. 1242-1249, 2005.

[274] L. Wang, M. Szklo, A. R. Folsom, N. R. Cook, S. M. Gapstur, and P. Ouyang, "Endogenous sex hormones, blood pressure change, and risk of hypertension in postmenopausal women: the multi-ethnic study of atherosclerosis," Atherosclerosis, vol. 224, no. 1, pp. 228-234, 2012.

[275] D. Zhao, E. Guallar, P. Ouyang et al., "Endogenous sex hormones and incident cardiovascular disease in postmenopausal women," Journal of the American College of Cardiology, vol. 71, no. 22, pp. 2555-2566, 2018.

[276] J. E. Morley and H. M. Perry III, "Androgens and women at the menopause and beyond," The Journals of Gerontology Series A Biological Sciences and Medical Sciences, vol. 58, no. 5, pp. M409-M416, 2003.

[277] A. Kaczmarek, K. Reczuch, J. Majda, W. Banasiak, and P. Ponikowski, "The association of lower testosterone level with coronary artery disease in postmenopausal women," International Journal of Cardiology, vol. 87, no. 1, pp. 53-57, 2003.

[278] Y. E. Kang, J. M. Kim, K. H. Joung et al., "The roles of adipokines, proinflammatory cytokines, and adipose tissue macrophages in obesity-associated insulin resistance in modest obesity and early metabolic dysfunction," PLoS One, vol. 11, no. 4, Article ID e0154003, 2016.

[279] A. Salgado-Somoza, E. Teijeira-Fernandez, A. L. Fernandez, J. R. Gonzalez-Juanatey, and S. Eiras, "Proteomic analysis of epicardial and subcutaneous adipose tissue reveals differences in proteins involved in oxidative stress," American Journal of Physiology-Heart and Circulatory Physiology, vol. 299, no. 1, pp. H202-H209, 2010.

[280] F. Samad, M. Pandey, and D. J. Loskutoff, "Regulation of tissue factor gene expression in obesity," Blood, vol. 98, pp. 3353-3358, 2001.

[281] A. Tschoner, W. Sturm, J. Engl et al., "Plasminogen activator inhibitor 1 and visceral obesity during pronounced weight loss after bariatric surgery," Nutrition, Metabolism \& Cardiovascular Diseases, vol. 22, no. 4, pp. 340-346, 2012.

[282] D. Wu, Z. Ren, M. Pae et al., "Aging up-regulates expression of inflammatory mediators in mouse adipose tissue," The Journal of Immunology, vol. 179, no. 7, pp. 4829-4839, 2007.

[283] F. Mascarenhas-Melo, J. Sereno, E. Teixeira-Lemos et al., "Markers of increased cardiovascular risk in postmenopausal women: focus on oxidized-LDL and HDL subpopulations," Disease Markers, vol. 35, pp. 85-96, 2013.

[284] K. A. Matthews, S. L. Crawford, C. U. Chae et al., "Are changes in cardiovascular disease risk factors in midlife women due to chronological aging or to the menopausal transition?" Journal of the American College of Cardiology, vol. 54, pp. 2366-2373, 2009.

[285] C. Gomez-Santos, J. J. Hernandez-Morante, F. J. Tebar, E. Granero, and M. Garaulet, "Differential effect of oral dehydroepiandrosterone-sulphate on metabolic syndrome features in pre- and postmenopausal obese women," Clinical Endocrinology, vol. 77, pp. 548-554, 2012.

[286] A. Lasco, N. Frisina, N. Morabito et al., "Metabolic effects of dehydroepiandrosterone replacement therapy in postmenopausal women," European Journal of Endocrinology, vol. 145, pp. 457-461, 2001. 
[287] R. A. Kloner, C. Carson III, A. Dobs, S. Kopecky, and E. R. Mohler III, "Reply: testosterone and cardiac diastolic function," Journal of the American College of Cardiology, vol. 68, no. 5, pp. 574-575, 2016.

[288] F. B. Hu, F. Grodstein, C. H. Hennekens et al., "Age at natural menopause and risk of cardiovascular disease," Archives of Internal Medicine, vol. 159, no. 10, pp. 1061-1066, 1999.

[289] S. Tsang, S. Wu, J. Liu, and T. M. Wong, “Testosterone protects rat hearts against ischaemic insults by enhancing the effects of $\alpha_{1}$-adrenoceptor stimulation," British Journal of Pharmacology, vol. 153, no. 4, pp. 693-709, 2008.

[290] P. C. Rezende, F. F. Ribas, C. V. Serrano Jr., and W. Hueb, "Clinical significance of chronic myocardial ischemia in coronary artery disease patients," The Journal of Thoracic Disease, vol. 11, no. 3, pp. 1005-1015, 2019.

[291] K. M. English, "Men with coronary artery disease have lower levels of androgens than men with normal coronary angiograms," European Heart Journal, vol. 21, no. 11, pp. 890-894, 2000.

[292] K. M. English, R. P. Steeds, T. H. Jones, M. J. Diver, and K. S. Channer, "Low-dose transdermal testosterone therapy improves angina threshold in men with chronic stable angina: a randomized, double-blind, placebo-controlled study," Circulation, vol. 102, no. 16, pp. 1906-1911, 2000.

[293] F. Callies, H. Strömer, R. H. G. Schwinger et al., "Administration of testosterone is associated with a reduced susceptibility to myocardial ischemia," Endocrinology, vol. 144, no. 10, pp. 4478-4483, 2003.

[294] C. M. Webb, J. G. McNeill, C. S. Hayward, D. de Zeigler, and P. Collins, "Effects of testosterone on coronary vasomotor regulation in men with coronary heart disease," Circulation, vol. 100, no. 16, pp. 1690-1696, 1999.

[295] A. P. Waldenstrom, A. C. Hjalmarson, and L. Thornell, “A possible role of noradrenaline in the development of myocardial infarction: an experimental study in the isolated rat heart," American Heart Journal, vol. 95, no. 1, pp. 43-51, 1978.

[296] A. Schomig and G. Richardt, "The role of catecholamines in ischemia," Journal of Cardiovascular Pharmacology and Therapeutics, vol. 16, no. 5, pp. S105-S112, 1990.

[297] T. D. O’Connell, " $\alpha \alpha_{1}$-adrenergic receptors prevent a maladaptive cardiac response to pressure overload," Journal of Clinical Investigation, vol. 116, no. 4, pp. 1005-1015, 2006.

[298] S. Engelhardt, P. Boknik, U. Keller, J. Neumann, M. J. Lohse, and L. Hein, "Early impairment of calcium handling and altered expression of junctin in hearts of mice overexpressing the $\beta_{1}$-adrenergic receptor," The FASEB Journal, vol. 15, no. 14, pp. 2718-2720, 2001.

[299] X. J. Du, H. Kiriazis, X. Moore et al., “Transgenic $\alpha_{1 \mathrm{~A}}$-adrenergic activation limits post-infarct ventricular remodeling and dysfunction and improves survival," Cardiovascular Research, vol. 71, no. 4, pp. 735-743, 2006.

[300] F. Lin, W. Andrew Owens, S. Chen et al., "Targeted $\alpha_{1 \mathrm{~A}^{-}}$ adrenergic receptor overexpression induces enhanced cardiac contractility but not hypertrophy," Circulation Research, vol. 89, no. 4, pp. 343-350, 2001.

[301] S. Tsang, S. S. Wong, S. Wu, G. M. Kravtsov, and T. M. Wong, "Testosterone-augmented contractile responses to $\alpha_{1}$ - and $\beta_{1}$-adrenoceptor stimulation are associated with increased activities of RyR, SERCA, and NCX in the heart," American Journal of Physiology-Cell Physiology, vol. 296, no. 4, pp. C766-C782, 2009.
[302] C. Communal, K. Singh, D. B. Sawyer, and W. S. Colucci, "Opposing effects of $\beta_{1^{-}}$and $\beta_{2}$-adrenergic receptors on cardiac myocyte apoptosis: role of a pertussis toxin-sensitive G protein," Circulation, vol. 100, no. 22, pp. 2210-2212, 1999.

[303] E. A. Jankowska, B. Biel, J. Majda et al., "Anabolic deficiency in men with chronic heart failure: prevalence and detrimental impact on survival," Circulation, vol. 114, no. 17, pp. 1829-1837, 2006.

[304] C. Malkin, T. Jones, and K. Channer, "Testosterone in chronic heart failure," Frontiers of Hormone Research, Advances in the Management of Testosterone Deficiency, vol. 37, pp. 183-196, 2009.

[305] P. E. Kontoleon, M. I. Anastasiou-Nana, P. D. Papapetrou et al., "Hormonal profile in patients with congestive heart failure," International Journal of Cardiology, vol. 87, no. 2-3, pp. 179-183, 2003.

[306] J. J. Naghi, K. J. Philip, D. DiLibero, R. Willix, and E. R. Schwarz, "Testosterone therapy: treatment of metabolic disturbances in heart failure," Journal of Cardiovascular Pharmacology and Therapeutics, vol. 16, no. 1, pp. 14-23, 2011.

[307] M. Kazi, S. A. Geraci, and C. A. Koch, "Considerations for the diagnosis and treatment of testosterone deficiency in elderly men," The American Journal of Medicine, vol. 120, no. 10 , pp. 835-840, 2007.

[308] U. A. Khan, M. Aslam, and S. A. Saeed, "Effect of beta adrenergic antagonist on the production of testosterone by rat's Leydig cells," Journal of Ayub Medical College Abbottabad, vol. 16, pp. 26-28, 2004.

[309] Q. Chen, Z. Fu, X. Wu et al., “Association of serum androgen concentrations with cardiovascular risk factors in elderly male patients with chronic systolic heart failure in China," Aging Male, vol. 17, no. 3, pp. 155-160, 2014.

[310] P. J. Pugh, T. H. Jones, and K. S. Channer, "Acute haemodynamic effects of testosterone in men with chronic heart failure," European Heart Journal, vol. 24, no. 10, pp. 909-915, 2003.

[311] J. D. Bisognano, H. D. Weinberger, T. J. Bohlmeyer et al., "Myocardial-directed overexpression of the human $\beta_{1}$-adrenergic receptor in transgenic mice," Journal of Molecular and Cellular Cardiology, vol. 32, no. 5, pp. 817-830, 2000.

[312] Q. Yin, C. Yang, J. Wu et al., "Downregulation of $\beta$-adrenoceptors in isoproterenol-induced cardiac remodeling through HuR," PLoS One, vol. 11, no. 4, Article ID e0152005, 2016.

[313] D. Leosco, V. Parisi, G. D. Femminella et al., "Effects of exercise training on cardiovascular adrenergic system," Frontiers in Physiology, vol. 4, p. 348, 2013.

[314] S. M. MacDonnell, H. Kubo, D. L. Crabbe et al., "Improved myocardial $\beta$-adrenergic responsiveness and signaling with exercise training in hypertension," Circulation, vol. 111, no. 25 , pp. $3420-3428,2005$.

[315] D. Leosco, G. Rengo, G. Iaccarino et al., "Exercise training and $\beta$-blocker treatment ameliorate age-dependent impairment of $\beta$-adrenergic receptor signaling and enhance cardiac responsiveness to adrenergic stimulation," American Journal of Physiology-Heart and Circulatory Physiology, vol. 293, no. 3, pp. H1596-H1603, 2007.

[316] D. Leosco, G. Iaccarino, E. Cipolletta et al., "Exercise restores $\beta$-adrenergic vasorelaxation in aged rat carotid arteries," American Journal of Physiology-Heart and Circulatory Physiology, vol. 285, no. 1, pp. H369-H374, 2003.

[317] A. F. Melo Junior, P. L. M. Dalpiaz, G. J. Sousa et al., "Nandrolone alter left ventricular contractility and promotes 
remodelling involving calcium-handling proteins and reninangiotensin system in male SHR," Life Sciences, vol. 208, pp. 239-245, 2018.

[318] F. Hartgens and H. Kuipers, "Effects of androgenic-anabolic steroids in athletes," Sports Medicine, vol. 34, no. 8, pp. 513-554, 2004.

[319] S. Rogerson, R. P. Weatherby, G. B. Deakin et al., "The effect of short-term use of testosterone enanthate on muscular strength and power in healthy young men," Journal of Strength and Conditioning Research, vol. 21, no. 2, pp. 354-361, 2007.

[320] I. Riezzo, M. D. Paolo, M. Neri et al., "Anabolic steroid- and exercise-induced cardio-depressant cytokines and myocardial $\beta_{1}$ receptor expression in CD1 mice," Current Pharmaceutical Biotechnology, vol. 12, no. 2, pp. 275-284, 2011.

[321] R. S. Tan and M. C. Scally, "Anabolic steroid-induced hypogonadism--towards a unified hypothesis of anabolic steroid action," Medical Hypotheses, vol. 72, pp. 723-728, 2009.

[322] A. P. Tanno, V. J. das Neves, K. Teodoro Rosa et al., "Nandrolone and resistance training induce heart remodeling: role of fetal genes and implications for cardiac pathophysiology," Life Sciences, vol. 89, no. 17-18, pp. 631-637, 2011.

[323] E. F. Du Toit, E. Rossouw, J. Van Rooyen, and A. Lochner, "Proposed mechanisms for the anabolic steroid-induced increase in myocardial susceptibility to ischaemia/reperfusion injury," Cardiovascular Journal of Africa, vol. 16, pp. 21-28, 2005.

[324] V. J. das Neves, A. P. Tanno, T. S. Cunha et al., "Effects of nandrolone and resistance training on the blood pressure, cardiac electrophysiology, and expression of atrial $\beta$-adrenergic receptors," Life Sciences, vol. 92, no. 20-21, pp. 1029-1035, 2013. 